\title{
EL DATIVO LATINO: INTERPRETACIONES Y BIBLIOGRAFÍA EN LOS DOS ÚLTIMOS SIGLOS
}

Marco Antonio Gutiérrez Galindo Universidad del País Vasco - UPV/EHU

El presente artículo persigue dos objetivos fundamentales: de un lado, ofrecemos una visión crítica de los logros y deficiencias que podemos encontrar en los principales estudios sobre el dativo latino en los dos últimos siglos; de otro, ofrecemos una relación exhaustiva de dichos trabajos. De nuestro análisis se desprende, además, que cualquier teoría sintáctia encuentra en el dativo (latino) una apropiada piedra de toque para validar sus posiblidades.

\section{INTERPRETACIONES}

\section{Introducción}

Una fama inmerecida, debida sobre todo al sugerente título «Pour une histoire du datif latin», alcanzó Laborderie con un trabajo publicado en 1934 que ciertamente prometía más que daba ${ }^{1}$. No obstante, tiene el citado estudioso el mérito de haber puesto el dedo en una llaga que estaría supurando hasta nuestros días cuando - a buen seguro que no por casualidad - escribió (1934, p. 280): «C'est seulement au prix d'un dépouillement long et minutieux que l'on pourra donner une réponse à un problème irritant qui intéresse autant la stylistique que la syntaxe». De hecho, ya Marouzeau 1928, p. 262, unos años antes había señalado: «il reste ancore à écrire une histoire interne du datif, en suivant plus rigoureusement qu'on ne l'a fait jusqu'ici les étapes

\footnotetext{
1 Intentos de analizar el dativo en otras lenguas ya se habían realizado con anterioridad; así Guest 1842-1844 para el inglés, Dietrich 1851 para el escandinavo o Semple 1895 para el dativo "in general", pues en este último estudio se somenten a consideración ejemplos de diversas lenguas.
} 
attestées par les documents littéraires». El propio Marouzeau señala unas líneas antes: «J'ai étudié naguère, sans espoir de le réaliser jamais moi-même, un projet de monographie sur le datif latin»; y no le duelen prendas en reconocer a renglón seguido que se trata de «un sujet que M. Löfstedt recommande aussi ${ }^{2} \gg$. No debemos olvidar, en fin, que como telón de fondo de todas estas buenas intenciones estaba el interés que suscitó la monografía titulada De dativo Latino, publicada por Gustafsson en 1904 y en la que se defendía todavía la teoría localista ${ }^{3}$.

Lo más atractivo de la nota-artículo (que apenas ocupa tres páginas) de Laborderie es la promesa por parte de su autor de un trabajo en profundidad sobre el uso del dativo latino. No obstante, dicho libro - hasta donde nosotros hemos podido indagar - nunca se llegó a publicar. Más aún, la monografía sobre el dativo latino que Marouzeau, Laborderie y otros intuyeron como tarea compleja, pero igualmente necesaria, está todavía por realizarse, y no dudamos que sería bienvenida tanto entre los latinistas como entre los restantes lingüistas. Este vacío entendemos que no es un hecho sin importancia en unos momentos como los presentes, en que el estudio de dicho tema ha recibido un trato preferente, fruto sin duda de la relevancia que el análisis del dativo/la datividad ha adquirido en los planteamientos teóricos de las corrientes lingüísticas más recientes ${ }^{4}$. Así y todo, cumple recordar que en la excelente síntesis que Calboli 1983 elabora sobre los "Problemi di grammatica latina" en las modernas corrientes lingüísticas sólo dedica unas breves líneas al dativo (pp. 34-35), y en ellas sólo alude a estudios gramaticales latinos de carácter general, como los de Scherer 1975, E. Löfstedt $1942^{2}$ o Hofmann-

2 En sus Syntactica, 1928-1933, t. I, p. 154ss.

3 Sin duda que se trataba de una monografía que pronto llamó la atención de los estudiosos; en tal sentido pueden leerse también los comentarios del propio E. Löfstedt 19281933, t. I, pp. 152-154, y los de Lejay 1907, p. 206; este último formula la siguiente observación: «une question qu'il eût été bon de discuter à fond ... était la substitution du datif à une construction prépositionnelle». Muchos años más tarde Colucci 1981, p. 14, n. 6, escribirá al respecto: «il dativo latino como caso tipicamente locale costituisce invece la tesi, ingegnosa quando azzardata, di F. Gustavsson (sic)».

4 Los propios latinistas también le han dedicado una cierta atención. Por ello, no es casual que se dedicara el I Encuentro de sintaxis latina (Miraflores de la Sierrra, Madrid, 10-11 de junio de 1994) a la sintaxis del dativo latino. Sus actas fueron editadas por Torrego, Quetglas y Espinilla (1995). Por lo demás, cumple recordar aquí las dos versiones del estudio de Hoecke (1994, vers. francesa, 1996, vers. inglesa) sobre el dativo latino, donde se ofrece una síntesis de las teorías que al respecto ofrecen las gramáticas tradicionales y las recientes corrientes lingüísticas, en particular las que podríamos calificar de funcionalistas. 
Szantyr 1972; de manera accidental o marginal cita a Fillmore 1977, a Murru 1979b, y a Dowty 1978 a propósito del dativo (Calboli, 1983, pp. 66-67, 77, 77, 77-78, respectivamente).

En las líneas que siguen trataremos de mostrar los diferentes enfoques que el estudio sintáctico del caso en cuestión ha recibido a lo largo de los siglos XIX y XX. Nos centraremos de manera particular y exhaustiva en los estudios concernientes al dativo latino. Con todo, habrá también alguna referencia a trabajos sobre el dativo en otras lenguas, siempre y cuando ello nos ayude a comprender mejor los motivos que los justificaron y el alcance real de los mismos en relación a las premisas teóricas y metodológicas en que se inspiraron.

\section{El dativo en las teorías sintácticas del s. $X X^{5}$}

\subsection{La pionera monografía de F. Gustafsson}

A principios del s. XX aparece la primera monografía propiamente dicha sobre el dativo latino. Fue escrita por el latinista finlandés Gustafsson y publicado en Helsinki en 1904. Se trata de una obrita de 75 páginas muy citada después en todo tipo de gramáticas y estudios acerca del dativo latino, pero realmente poco conocida de primera mano y menos aún leída en su totali$\operatorname{dad}^{6}$.

Tres son los motivos por los que tiene un especial interés para nuestros

5 Para un análisis general sobre el trato que recibió el dativo en los estudios gramaticales de los siglos XIX y XX nos remitimos a Gutiérrez Galindo (en prensa).

6 Buena prueba de ello es el siguiente hecho: Cousin 1951, p. 117, en la sección de su bibliografía dedicada al dativo latino, menciona el libro de Gustafsson (que aparece grafiado como Gustaffson) y entre corchetes aclara al final de su cita: «[reprend une étude de 1898]», pero no aclara de qué estudio se trata. Lo cierto es que el propio Gustafsson al inicio de su obra (nota 1) ofrece la cita completa de este trabajo germinal, que vio la luz en 1899. Pero no es éste de 1899 el único trabajo suyo que Gustafsson cita en su monografía sobre el dativo, también se alude en otro momento $(1904$, p. 59, n. 1) a un estudio sobre el gerundio y gerundivo publicado en 1903, si bien es cierto que en este último las alusiones al dativo como tal sólo son esporádicas. Téngase en cuenta, por lo demás, que la intención del autor es (de)mostrar la validez de la propuesta localista, más que argumentar contra las teorías antilocalistas, a las que sólo alude de forma esporádica (1904, pp. 48, n.1, 53, n.1, 70). Por lo demás, los datos bibliográficos que ofrece la citada obra de Cousin sobre el dativo latino contienen alguna imprecisión más: p. ej., se cita la nota de Meillet 1924b, p. 104, titulada «Latin interdico», si bien dicho autor se refiere en ella más bien al ablativo: «l'emploi de l'ablatif pour indiquer l'objet interdit est común à l'avestique et au latin». 
propósito la obra que nos ocupa. Para empezar, porque era la primera vez (hasta donde nosotros hemos podido llegar) que un autor escribía un estudio sobre el dativo latino desde el punto de vista de la teoría sintáctica, y no una mera descripción y enumeración de usos y valores gramaticales, como sucede p. ej. con el tratado de Peine 1878, varias veces citado por Gustafsson.

También es de reseñar que el objetivo último de su autor no era sólo confirmar o demostrar que el dativo latino era un caso local, sino que los presupuestos de la teoría localista son aplicables al sistema casual latino (y no latino); ello justifica que las últimas páginas de su estudio (pp. 70-75) estén dedicadas a (de-)mostrar el carácter localista del resto de los casos (con la salvedad del nominativo), proyectando sobre ellos directa o indirectamente los logros obtenidos al respecto en el estudio del dativo.

Por otro lado, convendría tener presentes las siguientes palabras que Gustafsson (1904, p. 1) escribe al inicio de su obra: In fennico igitur sermone, ubi non est habendi uerbum, est dandi uerbum, datiui casus munera sustinent locales casus, qui quidem complures ac uarii sunt. En efecto, la cita precedente parece sugerir dos hechos importantes: de un lado, que en alguna lengua no indoeuropea (como pueda ser el finés) el dativo tiene una particular relevancia; de otro, que los presupuestos de las teorías localistas parecen adaptarse mejor al estado de cosas que se advierte en dicha(s) lengua(s). De esta forma Gustafsson se convierte en un precedente de Hjemslev 1935-1937, 1978, circunstancia que convendría no pasar por alto, como a veces sucede.

Así las cosas, no resulta difícil imaginarse el interés del latinista finlandés por analizar con detalle el dativo latino desde la perspectiva localista, que todavía se mantenía vigorosa en los albores del siglo XX. A su vez, el propio punto de partida metodológico desde el que se desarrolla el contenido del libro justifica que en cada momento se aprovechen todos los resquicios favorables a la causa, provengan de donde provengan. A veces se prolonga la sombra del valor semántico (local) hasta hacer que se solape con el sintáctico (de dativo), como ocurre con el adjetivo proximus (Gustafsson, 1904, p. 6 ss.). En ocasiones semántica y morfología se dan la mano (p. 16): "in personali dativo latino plurima restant vestigia primae significationis localis"; ni siquiera le resulta ajeno a su causa (p. 71, n.1) el psicologismo de Wundt, por más que éste pensara que los aparentes usos locales del dativo eran debidos a una secundaria asociación con un caso directivo (Wundt, $1912^{3}$, t. II, p. 120).

Por lo demás, Gustafsson se sirve de los tópicos que le son propios a las teorías localistas, aunque a veces el deseo de llevar hasta sus últimas conse- 
cuencias los presupuestos localistas le oblige a construir gradaciones tan artificiosas como la siguiente (1904, p. 55): Quos per gradus hic datiuus ethicus sensualis, localis ad magis abstractum descenderit, haud difficile erit exemplis probare huic esse cognatum.

\subsection{Teorías sobre el dativo latino en las primeras décadas}

En 1925 Kroll publicaba un breve tratado de gramática latina titulado Die wissenschaftliche Syntax im lateinischen Unterricht (traducido como La sintaxis científica en la enseñanza del latín). A pesar de la época en que fue publicado y a pesar de tratarse de una obra breve, eso no le impidió a su autor decir, al principio del capítulo dedicado a la teoría sobre el sistema casual $(1925=1935$, pp. 37-38): «si los fenómenos lingüísticos, que por su naturaleza son complejos, se dejan reducir a fórmulas sencillas, debemos felicitarnos de ello como de una suerte. Pero no se debe hacer violencia a los hechos para lograr ese fin». Entendemos que la opinión precedente tiene un valor particular por tratarse de una obra "pedagógica", proclive - al menos en principio - a simplificar la diversidad de datos en aras de una comprensión más rápida y eficaz de los mismos. Más aún, pese a que el propio Kroll (p. 5) dice en el Prólogo de su obra que no intenta "decir nada nuevo a los conocedores de la materia", y pese a que su oposición a la teoría casual localista es una más, lo cierto es que hasta entonces no se había formulado ninguna teoría no localista propiamente sintáctica del sistema casual latino. No es, por tanto, de extrañar que unos años más tarde, cuando E. Löfstedt 1928-1933, t. I, p. 154, n.1, acometa esta labor en sus aspectos fundamentales, se adhiera a la opinión de Kroll y cite expresamente unas palabras suyas que preceden a las mencionadas por nosotros un poco más arriba (esto es, pp. 37-38): «en este esfuerzo por reducir todos los casos a una significación fundamental localística, no puedo ver más que una recaída en la misma manía de uniformidad, que dominó en la época del método lógico» (citamos según la edición de Kroll, $1925=1935$, p. 37). Sobre este aspecto volveremos más adelante, en $§ 3.6$.

Aunque la citada obra de E. Löfstedt es de índole general, es significativo que al principio del apartado que se dedica al dativo ( Zur Entwiclung des Dativs») se diga (1928-1933, t. I, p. 145): «Dass das Wessen des leteinischen Dativs in den letzten Jahrzehnten besonders lebhaft diskutiert worden ist, hängt zum Teil mit dem Kampf um die lokalistische Kasustheorie zusammen, indem dir Vertreter dieser Theorie den Dativ als ein Wichtiges 
und interessantes Beispiel für die Richtigkeit ihrer Auffassung betrachten».

Hay una circunstancia en el trabajo de E. Löfstedt que nos parece sorprendente, a saber, en la severa crítica que hace de la teoría localista toma una y otra vez como referencia la obra de Gustafsson 1904, mientras que la valiosa obra de Bennett 1910-1914, t. II, se cita de pasada y sólo esporádicamente. Este hecho es llamativo tanto porque la obra de Bennett es posterior a la de Gustafsson - y además muy detallada -, como porque la monografía de este último, a pesar de su título (De dativo Latino), hace referencia a otros muchos sistemas casuales diferentes del latino.

Las coordenadas que definen el enfoque metodológico de E. Löfstedt, diferenciándolo de los anteriores y haciéndolo realmente valioso para la posteridad, podemos sintetizarlas en los siguientes puntos:

1. Rechaza de manera genérica el localismo por considerar que conduce a una rigidez (propia del logicismo) que atenta contra los hechos de la lengua; para ello se vale de principios tomados del ámbito psicológico y de ejemplos concretos de la lengua que refutan tales planteamientos.

2. Critica la falta de rigor filológico en la interpretación histórica o/y contextual que Gustafsson hace de muchos de los ejemplos aducidos, sean tanto de época arcaica, como clásica o tardía ${ }^{7}$;

3. Esta sintaxis filológica practicada por E. Löfstedt - que no en vano se considera ante todo un filólogo (p. 149) - le hace dar un paso más en su análisis gramatical, de suerte que no sólo importan las relaciones paradigmáticas entre los casos, sino las relaciones paradigmáticas de oposición o/y complementariedad entre cada caso y las construcciones que pueden entrar en concurrencia con él ${ }^{8}$; muchas son las páginas que dedica a tal menester, y no pocas las sutilidades que su fino análisis de los datos logra destilar ${ }^{9}(23)$.

7 No sólo son interesantes las puntualizaciones que hace en este capítulo sobre uso y valor del dativo en el latín tardío, también reflexiona al respecto en el segundo tomo de sus Syntactica (1928-1933, t. II, p. 389ss.), e igualmente en su Il latino tardo $(1959=1980$, pp. 182-186).

8 El propio E. Löfstedt 1928-1933, t. I, p. 155, al enunciar tal principio se daba cuenta de la modernidad del mismo: «muss hier wie bei jeder modernen syntaktischen Monographie nicht nur der Kasus als solcher, sondern ebenso -sehr die Ersatzmittel desselben, d. h. die damit konkurrieren- den Ausdrucksformen, berücksichtigt werden».

9 Un particular interés muestra E. Löftstedt por el llamado datiuus sympatheticus, sobre el que habla en este mismo capítulo (1928-1933, t. I, pp. 164-172) y al que más tarde dedica el capítulo 12 en exclusiva (t. I, pp. 173-185). 
Numerosas fueron las gramáticas latinas que se escribieron (o re-escribieron) en la primera mitad del s. $\mathrm{XX}^{10}$. La propia finalidad de tales tratados justifica que las opiniones vertidas allí sean en su mayor parte reflejo de la communis opinio de la época. En lo que concierne al dativo, podemos hablar de tres circunstancias que condicionan generalmente, de forma explícita o implícita, las exposiciones:

1. Los resultados de la disputa localistas/antilocalistas del siglo anterior.

2. Los resultados obtenidos por E. Löfstedt con su método sintácticofilológico frente al localismo.

3. Las consideraciones que desde hacía algún tiempo se venían haciendo sobre el dativo que acompaña a los verbos compuestos; sobre este punto insistiremos en $\S 2.3$.

Como es natural, cada gramática ofrece una solución de compromiso diferente en lo que se refiere a los detalles que explican la relación entre sí de los diferentes usos del dativo. Así y todo, con el paso del tiempo se irá imponiendo una bipartición básica que opone "dativos regidos" (básicamente el de C. Indirecto) a "dativos libres" (que tiene en el datiuus iudicantis su máximo exponente), y deja como residuales los dativos de dirección .

No es preciso decir que este estado de cosas es justamente el opuesto al que nos ofrece Bennett 1910-1914, t. II, último gran paladín de la teoría localista en el ámbito de la filología latina, como se ha hecho notar más arriba. No obstante, un análisis incluso superficial de los postulados de Bennett deja ver enseguida que la endeblez de sus argumentos preludia ya el estado de cosas que acabamos de describir como representativo de mediados del siglo XX.

Para dar cuenta de ello bastarán unas breves referencias. Bennett 19101914, t. II, p. 132, distingue teóricamente entre unos dativos (los de C. Indirecto) «closely associated with the verb» y otros (los de "referencia") que «modify the sentence as a whole». Pero en la práctica entiende que «a sharp line of demarcation ... cannot be drawn». Más aún, añade a acontinaución «The two types of use naturally merge into each other, as with many other

10 Para no extendernos demasiado en la cita de todas ellas, véanse en el Anexo bibliográfico II las referencias oportunas, desde la obra de Stolz y Schmalz $1910^{4}$ hasta la de Ernout y Thomas $1953^{2}$, pasando por las de Riemann 1886, rev. por P. Lejay 1894, 1900, 1907 y 1920, y rev. por Ernout 1925, Kühner y Stegmann 1912-1914², 1955, 1962, Devoto 1940, Tovar 1946 o Bassols 1947, entre otros. 
case constructions», toda vez que «The notion of direction lies at the basis». De hecho, como llega a decir unas páginas más adelante (t. II, p. 159), «The Dative of Possession is a natural outgrowth of the direction idea, the thing possessed being conceived as lying in the direction of the possessor; as e.g. mihi negoti nil est». El propio Bennett (t. II, p. 148, n. 1) hace notar en otro momento que «the Dative of Separation is closely related with the Sympathetic Dative. Both are but an extension of the general use embraced under the Dative of Reference».

\subsection{El dativo latino y los verbos compuestos}

Uno de los puntos más olvidados actualmente en el ámbito de la sintaxis del dativo latino, pero que llegó a ser uno de los más relevantes - al menos desde el punto de vista cuantitativo - hasta las primeras décadas del s. XX, es el que concierne a los verbos compuestos que "rigen" dicho caso ${ }^{11}$. Por tal motivo merece que le dediquemos un poco de atención, pues la producción bibliográfica al respecto ni es escasa ni carace de interés, ya que nos pone al descubierto más de una disputa entre los latinistas.

Las cosas debían haber llegado a un punto crítico cuando Lease 1912a, p. 7 , (se) formula con un tono casi inquisitorial las siguientes preguntas al inicio de un artículo: «should the rule for prepositional compounds with the dative be banished from the Latin Grammar? If retained, should it be taught in the high school? What is the actual value of the rule? How does it help? How often does it mislead?»

De las anteriores palabras se desprenden los siguientes hechos básicos. En primer lugar, que en las gramáticas o tratados gramaticales, de forma explícita o implícita, se aceptaba como regla que los "verbos compuestos (con determinados prefijos) regían dativo". Su aplicación llegó sin duda a convertirse en una práctica abusiva, tanto en la teoría de los manuales como en la práctica de la enseñanza del latín. Ello justifica que ya Draeger 1878,

11 Por lo que respecta al origen concreto de dicha regla, transcribimos la siguiente cita que encontramos en Lease $1912^{\text {a }}$, p. 300: «In replay to a query regarding the originator of the rule in its present form, Professor J. Golling wrote, March 11th, 1912: "Es ist wohl sicher, dass die Regel in der vorliegenden Fassung in den Jahren zwischen 1848-1855 enstanden ist und zwar durfte F. Schultz der Autor sein"». Por otro lado, para que pueda comprenderse adecuadamente toda esta polémica es preciso tener en cuenta la rígida metodología utilizada en esta época para la enseñanza del latín; de ello podría darnos una idea un breve artículo publicado por Kirtland 1912 el mismo año y en la misma revista que el de Lease $1912^{\mathrm{a}}$. 
t. I, p. 377, en su Historische Syntax der lateinischen Sprache levantara la voz contra la eficacia de dicha dicha regla ${ }^{12}$. No debió tener mucho éxito su queja, pues Fay 1911, p. 194, tuvo que arremeter de nuevo, en los siguientes términos: «the rule for the dative with compound verbs has long seemed to me a regular lazy-bed for grammarians; for pupils a very opiate and narcotic to reflection» ${ }^{13}$.

En relación a los puntos de vista expresados por Lease y Fay objeta Bennett $1910-1914$, t. II, p. 123, respectivamente, que «it is only sometimes true», y que «Fay's contention does not seem to me well supported by the material submitted in the following list».

La hetereogeneidad de este apartado en relación con los demás, incluso en un autor como Bennett que da una visión unitaria del dativo, queda puesta de manifiesto en su forma de proceder. En efecto, dicho autor (t. II, p. 123) dice en un momento determinado «I have always treated these datives as a variety of indirect object», y un poco más adelante (t. II, p. 124) «an embarrassment in classification results from the fact that many compound verbs governing the dative are also verbs of the 'special meanings ...; It has seemed to me better to exclude examples like these last from the 'Dative with Prepositional Compounds' and to bring them either under the 'Dative with verbs of Special meanings', or the 'Dative of Simple Indirect Object'».

No es asunto baladí recordar que la lista de Bennett (t. II, pp. 124-132) se extiende a lo largo de nueve densas páginas ${ }^{14}$. Antes que él son muchos los tra-

12 Draeger 1878 , t. I, p. 406, nota, en su obra magna se remite sobre este asunto a los trabajos previos de Hildebrand 1854, 1865, y, particularmente, de Augustin 1869. Reisig 1888 , t. III, pp. 597-599, nota 541e, ofrece una detallada nómina de trabajos de ésta época (segunda mitad del siglo XIX) sobre características gramaticales de autores particulares donde se van completando estas listas.

13 Se da la circunstancia de que las anteriores palabras de Fay aparecen significativamente repetidas por Lease en sendos artículos publicados el mismo año Lease, 1912a, p. 7; $1912 b$, p. 285. Como suele ocurrir en estos casos, también podemos encontrar trabajos donde se alude a las excepciones a la regla. De hecho, en algunos contextos el número y alcance de éstas supera al de la propia regla, lo que justifica el tono irónico del brevísimo (menos de una página real) artículo de Nutting 1920-1921, p. 369, al respecto y su alfilerazo final: «but even so sporadic a demonstration may prove the folly of blind reliance on the 'rule' and emphasize the fact that compounds are not all of one kind - whence their diverse construction». En épocas más recientes las cosas se han atemperado, al menos en la forma de enfocar el asunto; véanse, p. ej., Serbat 1996a, t. I, p. 554ss., o Echarte 1994.

14 Kühner-Stegmann $1912-1914^{2}$, t. II/1, p. 326 ss., por su parte, no le van a la zaga, y dedican un generoso espacio de casi diez páginas a los dativos "regidos" por verbos compues- 
bajos que de forma minuciosa recogen un sinnúmero de ejemplos; he aquí algunos botones de muestra referidos a los autores pioneros en dicha tarea ${ }^{15}$ : Lehmann $1863^{16}$, Augustin 1869, Ignatius 1877, Hahn 1878, Ulrich 1880, Oesterberg 1883, Teetz 1885, Lastavec $1899^{17}$.

\subsection{El dativo latino en el estructuralismo}

El sistema estructuralista de oposiciones binarias tuvo como principales introductores en el campo de la sintaxis a Hjelmslev 1935-1937 = 1978 y a Jakobson $1936=1975$. Moralejo 1986, p. 314, el último gran defensor del enfoque estructuralista, haría notar varias décadas más tarde que «el dativo es un caso que ha planteado más de una vez problemas de clasificación».

Siguiendo la estela estructuralista, de Groot 1939 y 1956 y Kurylowicz 1949 = 1960 y 1964 elaborarían varios trabajos en los que buscan afanosamente ofrecer una visión sistematizada del sistema casual indoeuropeo, que a menudo se ilustra con ejemplos latinos.

El lingüista holandés no debió sentirse muy satisfecho con su primera propuesta y elaboró una segunda (Groot 1956, p. 189). En ella el bloque acusativo-genitivo-ablativo-dativo opone al nominativo en tanto que éste no es portador de "significación casual" y aquéllos sí. La pareja ablativo-dativo se opone al acusativo porque aquéllos expresan una "relación específica" y éste una "no específica". Finalmente, el dativo y el ablativo se diferencian

tos transitivos e intransitivos, a pesar de tratarse de una Gramática, y no de una monografía.

15 No debe olvidarse, a su vez, que en algunos trabajos sobre el dativo en general también encontramos un apartado dedicado al tema en cuestión; así, p. ej., en el de Schlüter 1874, pp. 25-30, De accusatiui et datiui usu Terentiano, o en el de Peine 1878, De datiui usu apud priscos scriptores latinos.

16 Algunos autores, como Reisig 1888, pp. 591-592, n. 541b, Kühner-Stegmann 1912$1914^{2}$, t. II/2, pp. 326, 645, o Cousin 1951, p. 118, citan una edición de 1884 como «P.I.G. Prgr. Leobschütz»; Cousin, además, indica que tiene « $17 \mathrm{p} »$. Desconocemos esta edición, pero bien pudiera ser una versión abreviada de la original de 1863, que tiene 70 páginas.

17 Hay que advertir que el trabajo de Lastavec, hasta donde nosotros hemos podido llegar (pues sólo hemos tenido acceso a la copia manuscrita), está inédito, aunque Cousin 1951, p. 118, que lo grafía erróneamente como Lasravec, no advierte nada al respecto. Tal vez ello justifique su casi completo desconocimiento por parte de los latinistas, a pesar de tener cierto interés, sobre todo la bibliografía que de forma crítica menciona en el estudio introductorio (pp. 1-10). Por lo demás, cabría reseñar aquí algunos autores que aluden a trabajos sobre verbos compuestos latinos en general anteriores incluso a los que acabamos de citar sobre el dativo; los más antiguos de los que tenemos noticia son dos de Hildebrand (1854 y 1865), aludidos vagamente por Reisig 1888, p. 597, n. 541e. 
porque el primero expresa la "persona interesada en el proceso", en tanto que el otro "la causa inanimada del proceso".

El principal problema que encontramos en el proceso de descripción del dativo es la existencia de una fuerte asimetría: las dos primeras oposiciones son de tipo privativo, mientras que la última - la que le diferencia del ablativo - es equipolente. El hecho de que ésta sea la más específica la convierte en la más importante, pues impide establecer las coordenadas necesarias para determinar el valor relativo de dicho caso en relación al conjunto del sistema casual, con las consecuencias anteriormente descritas que ello acarrea. En los sistemas latinos propuestos más recientemente por Rubio $1989^{3}$ y Moralejo 1986 desde una perspectiva estructuralista encontramos un problema similar en lo que concierne al dativo ${ }^{18}$.

Kurylowicz también elaboró dos versiones de su teoría. En la segunda (1964, p. 190 ss.) el dativo tiene un papel muy secundario, toda vez que sólo es considerado como un subtipo del locativo.

\subsection{La asistematicidad del sistema casual latino}

Hace ya algún tiempo Serbat 1982 publicó un artículo con el inquisitivo título de «Le système casuel est-il systématique?» No era preciso ir más allá de las primeras líneas para percatarse de que la pregunta no tenía intención retórica en absoluto ${ }^{19}$. De hecho, lo que se perseguía era una severa crítica a los estructuralistas (de Meillet a Hjelmslev, y de Guillaume a Benveniste), para quienes "la langue est un système où tout se tient" (p. 298).

18 Mellado 1996, p. 101, sigue de cerca el esquema y los postulados propuestos por Moralejo 1986 para el estudio del sistema casual latino, pero cree que la caracterización de los casos no debe plantearse «en torno al verbo, sino al predicado». Con esta propuesta intenta justificar con mayor rigor de método los dativos llamados "adnominales" que «se han venido considerando "sueltos", como algo fuera del sistema», y equipararlos sintácticamente a los "adverbales".

19 Téngase presente que esta misma pregunta se la había planteado con anterioridad $\mathrm{Ku}$ rylowicz $1949=1960$, p. 144, aunque su respuesta fue muy diferente. Queremos dejar aquí constancia del siguiente hecho: los estudiosos que han puesto en tela de jucio la sistematicidad de la lengua en general (y del sistema casual en particular) a menudo han acompañado sus críticas de sutiles observaciones que bien podríamos calificar de (pre-)pragmáticas. Uno de los primeros trabajos (donde se hagan consideraciones sobre el dativo latino) en los que hemos detectado tal circunstancia es el de Barss 1927 titulado signficativamente «The drammatic element in Latin Grammar»; su autor (p. 127) en un momento determinado no vacila en escribir: «... the hope that complete and perfect classification might be achieved. Vain hope!». 
En efecto, Serbat (p. 308) critica a los estructuralistas como error inicial que postulen «l'organisation absolument unitaire de l'ensemble des signifiés casuels», ya sea porque la realidad de la lengua no se compadece con tal principio, ya sea porque los propios estructuralistas en la puesta en práctica de tal principio se ven obligados a contradecirlo una y otra vez. En cierta medida, como el propio lingüista galo reconoce, la discusión nos llevaría a la vieja polémica analogía/anomalía. De hecho, Serbat (p. 307 ss.) retrotrae sus observaciones hasta las viejas teorías semántico-localistas de Wüllner 1827.

Las críticas que acabamos de apuntar no debían ir muy desencaminadas cuando encontramos estudios recientes de corte estructuralista que dejan ya constancia de tales eventualidades. Así, p. ej., Moralejo 1986, p. 302, en su ponderada visión del sistema casual latino advierte también que «nos encontraremos con usos irreductibles a los valores casuales sugeridos por el criterio de empleo mayoritario lo que significa, simplemente, que en la categoría casual hay zonas no sistemáticas, disfunciones».

Por lo que hace algunos usos del dativo latino, como los que acompañan a los verbos inuidere o indulgere, piensa Serbat 1982, p. 311, que se explican mejor «comme des emplois vetustes de cas circonstanciels».

En un trabajo específico sobre el dativo y unos años posterior al anteriormente citado, Serbat 1989a, p. 229, señala que «le D(atif) est un Protée syntaxique», de suerte que no nos parece casualidad que unas líneas más adelante vuelva a preguntarse de nuevo: «peut-on sérieusement parler d'un 'système' casuel?».

Más recientemente y también mediante un título en interrogación («Les cas latins fonctionnent-ils en contre-emploi?») ha publicado Fugier 1998, p. 360 , un trabajo donde postula la posibilidad de «considérer les cas par sousensembles, chacun associé à une operation constructice de l'énoncé syntaxique», y que por lo tanto se encuentren «à un niveau plus élevé que celui des simples fonctions grammaticales».

Como Fugier (p. 360) reconoce, su propuesta es parcial y provisional, «car il restera à integrer dans le système casuel le D[atif] (comme complément de $\mathrm{V}$ et de $\mathrm{P}$ ) et l'ablatif». Con todo, entendemos que es de particular interés su novedosa propuesta de integrar en un mismo subsistema los casos Dativo y (en parte) Vocativo latinos, tal que ellos representan dentro de la lengua dos extremos con la posibilidad de contra-empleos que cumplan «une même fonction intégrative» (p. 359), que en la pareja de casos en cuestión sería la de "adressage". 


\subsection{El dativo en la gramática de valencias}

Tesnière 1959, p. 127, propuso la distinción entre "actants" y "circonstants", aunque hizo algunas matizaciones: «à première vue la limite entre actants et circonstants est nette. Mais, à y regarder de près, on s'aperçoit qu'elle est délicate à fixer avec précision. L'actant pourvu de l'indice numéral le plus élevé, c'est-à-dire, le tiers actant, présente déjà quelques caracteristiques de circonstant. Inversement, certains circonstants présentent avec les actants quelques analogies qui invitent à considérer attentivement les critériums susceptibles de permettre un départ entre les actants et les circonstants».

Se da la circunstancia de que el dativo es justamente el caso que se ve más afectado por las palabras anteriores. Sin embargo, las gramáticas de corte funcionalista, herederas directas de los postulados de Tesnière, no han prestado demasiada atención al problema de fondo que en ellas se plantea, que afecta de lleno al propio análisis del sistema casual. Por tal motivo no debemos extrañarnos que la valoración negativa que a Serbat $1981=1988$, p. 195, le merece la obra de Happ 1976, el autor que con mayor ahínco intentó aplicar al latín las tesis del gran lingüista galo: «la aplicación detallada que de ella (sc. de la Gramática de dependencias) ... ha hecho H. Happ al latín no es convincente».

Happ se sirve del llamado "test facere", que toma facere como un protoverbo con carga semántica casi nula: si tras un verbo puede añadirse la secuencia et id facit más el complemento en cuestión y la oración es gramatical, eso probaría que se trata de un C(ircunstante); en el caso contrario estaríamos ante un $\mathrm{A}$ (ctante).

Dicho test permite aislar y, en consecuencia, tomar como C los llamados dativos "libres" y los dativos "commodi et incommodi". Así, el ejemplo tibi aras es susceptible de traformarse en aras et id facis tibi. Sin embargo, esta operación no puede realizarse con huic rei student, a pesar de que todos los diccionarios proporcionan ejemplos absolutos de studere. Este mismo tipo de problemas se plantea con otros verbos como praeesse, prouidere y otros. De hecho, el propio Happ 1976, p. 407 ss., reconoce de forma explícita que el test en cuestión no funciona con el dativo "simpatético" del tipo que encontramos en el ejemplo Caesari ad pedes se proiecerunt.

Al lado de los "A obligatorios" coloca Happ un grupo que denomina "A facultativos", en tanto que elementos que pueden faltar libremente, si bien no pueden ser aislados mediante el aludido "test facere". Esta circunstancia, 
tras la que se esconde una cierta contradicción en los términos, afecta también a algunos dativos latinos, como por ejemplo los que acompañan a verbos como assideo o deesse.

Un último dato queremos añadir antes de terminar. Se da la circunstancia de que el único trabajo (que nosotros sepamos) sobre el dativo latino realizado desde los presupuestos teóricos de la Gramática de valencias es uno escrito en checo por E. Marečková-Štolková 1985, con un resumen en alemán al final del mismo. Su autora propone en él que una gran mayoría de usos del dativo latino responde, explícita o implícitamente, a un esquema triactancial.

La escuela funcionalista formada en torno a la figura del eximio lingüista holandés Dik ha sido uno de los herederos y continuadores más prolíficos de la llamada "Gramática de valencias". Por tal motivo no resulta sorprendente que el latinista Pinkster 1972, 1980, 1985, discípulo del propio Dik, haya dedicado varios trabajos al problema de los casos analizados desde la perspectiva en cuestión. Así y todo, los avances en este terreno han sido limitados.

En efecto, Pinkster $1990=1995$, p. 4, sigue hablando de constituyentes obligatorios y facultativos (aunque a los primeros los llame "argumentos" y a los otros "satélites"), omisibles los segundos, pero no los primeros. Dicho autor no habla de una categoría intermedia equiparable a la de los "Actantes facultativos" de Happ, pero hace notar (p. 14) que «la noción de "omisibilidad" implica ciertas consecuencias insatisfactorias». A su vez, sigue considerando válido el test de facere, si bien sugiere que en ocasiones pueden resultar más útiles para establecer la valencia "observaciones estadísticas" (p. 14 ss.).

El aludido latinista de Amsterdam, como su predecesores, no profundiza en la naturaleza del problema planteado por Tesnière acerca de las dificultaltades que presenta el estableciomiento de límites entre el segundo y tercer actantes. Ello justifica que las referencias al dativo sean muy escasas y esporádicas, hasta el punto de que el estatus sintáctico del dativo sólo puede deducirse a partir de tres Cuadros generales; en ellos se citan los siguientes ejemplos de dativos en tanto que argumentos (pp. 27, 28, 30): dedit pater librum filio; sunt proditores illi; est cara mater mihi; erat odio Hannibal Romanis; licet abire mihi. Los demás se supone que han de entenderse como satélites ${ }^{20}$.

20 Este desinterés por el dativo no es casual y se explica porque, al no haber solucionado de forma adecuada ni satisfactoria los problemas de principio que genera la teoría de las va- 
A pesar de los numerosos conflictos de interpretación suscitados entre los latinistas al analizar diversos usos del dativo, Pinkster sólo se detiene en una breve nota de un apartado de Observaciones (p. 28) para señalar a propósito del dativo "posesivo" que unos autores lo han considerado satélite (Scherer 1975, p. 126) y otros argumento (Happ 1976, p. 497; Lambertz 1982, p. 340; Bolkestein 1983, pp. 79-81) ${ }^{21}$.

La división funcionalista entre argumentos y satélites ha sido puesta en tela de juicio en más de una ocasión. Sirva como botón de muestra la enmienda a la totalidad que recientemente ha formulado Crespo 1997, t. II, p. 6.: «los predicados no se pueden clasificar según su valencia o número de complementos obligatorios. No hay complementos obligatorios cualitativamente distintos de los opcionales». Otros autores, como p. ej. Cabrillana 1997a, p. 328, han renunciado en la práctica a tal distinción: «teniendo en cuenta que en ocasiones no es fácil determinar la obligatoriedad de una serie de constituyentes en la predicación ..., he optado en este estudio por tratar metodológicamente la función de complemento de forma unitaria».

Como es natural tales dificultades de método han acabado afectando al estudio del dativo, hasta el punto de que Baños (1998, p. 24), que ha estudiado con tanto detalle el dativo latino, sostiene que «los datos comentados muestran hasta qué punto, en la caracterización del dativo "objeto indirecto", es irrelevante una distinción estricta entre argumentos y satélites» ${ }^{22}$.

lencias, los instrumentos que proporciona el método para tales menesteres son limitados. Ello justifica el limitado alcance innovador que reconoce de la Villa 1989, pp. 39-40, para los resultados de la aplicación del método funcionalista al estudio del dativo griego: «le résultat de notre recherche coïncide d'une manière partielle avec la vision historique traditionelle en ce qui concerne la reconnaisance des trois valeurs .... / ... il faul introduire en tant que possibilité fonctionnelle du datif dans le système fonctionnel grec, une quatrième fonction: "temps"». Por otro lado, a veces se producen situaciones sorprendentes (aunque no del todo inesperadas), como la que encontramos en van Hoecke 1996, t. I, pp. 31-32, que primero dice: «in Latin the dative forms a rather homogeneous case», y en la página siguiente parece dar por bueno que «according to Pinkster 1985, it is not always easy to establish whether the dative forms a consitutive element of the sentential kernel or not».

${ }^{21}$ Más recientemente, en el ámbito del español, Gutiérrez Ordóñez 1999 ha optado por considerarlo como "complemento no argumental". Para una discusión similar en relación al llamado datiuus auctoris puede verse el trabajo de Christol 1989.

22 El hecho, no casual, de que tanto Baños 1998, p. 25, como Cabrillana 1997a, p. 328, que parten de posiciones teóricas bastante parejas, hablen de la conveniencia de establecer una "gradualidad" o "gradación" en el estudio de los complementos, sugiere la oportunidad de encarar estos problemas desde una perspectiva que podríamos denominar genéricamente 


\section{Los diferentes tipos de dativo}

\subsection{El dativo en concurrencia con otros casos y construcciones}

El análisis funcionalista de la lengua ha puesto de manifiesto que el valor de un elemento se establece por sus relaciones con los otros con los que entra en concurrencia tanto en el paradigma como en el sintagma. Por ello, no es de extrañar que hayan menudeado los estudios en los que el dativo alterna en la frase con otros casos o/y construcciones para determinar si expresan o no las mismas funciones semánticas.

Dos son los aspectos en este punto que han suscitado particular interés entre los investigadores: el dativo posesivo en tanto que concurre con otras construcciones que indican posesión (sobre todo el genitivo), y los giros preposicionales que entran en concurrencia con algunos usos del dativo ${ }^{23}$.

El dativo posesivo (latino) ha interesado mucho a los gramáticos de diferentes épocas y adscripciones teóricas. De hecho, ya a finales del siglo XIX puede documentarse algún artículo al respecto (Miles 1897), o incluso monografías como las de Schenk 1892 y Schunk 1900. Merece citarse, por otro lado, la interpretación que Bennett 1910-1914, t. II, p. 159, consecuente hasta el final con sus posiciones localistas, hace al respecto: «the Dative of Possession is a natural outgrowth of the direction idea, the thing possessed being conceived as lying in the direction of the possessor». En el otro extremo está la tesis de Fay 1911, p. 195, que, coherente con su "doctrine of opposites", concluye que «the dative of possessor is an outgrowth from the dative of receiver». De hecho, este mismo autor (p. 190), siguiendo a Delbrück en el concepto y en la terminología, piensa que «the Latin Dative presents a true picture of the proethnic dative at the time of the upbreaking of the primitive stock».

Sin embargo, sería el imprescindible artículo de B. Löftstedt 1963 titulado «Zum lateinischen possessiven Dativ» el que contribuiría tanto a la con-

como de "cognitiva". Quisiéramos recordar aquí el trabajo algo olvidado de Lamaire 1983, que desde una perspectiva personal aborda este problema y sugiere prometedoras vías de investigación muy alejadas de los presupuestos funcionalistas que merecerían ser tomadas en cuenta de alguna manera, sobre todo porque ofrecen un horizonte de referencia mucho más acorde con la compleja realidad de la lengua.

23 Menos relevancia tiene, aunque merezca citarse por tratarse de un trabajo pionero, el estudio de Müller 1836 titulado Quaestio grammatica de Adiectivis, quae cum utroque casu et Genitivo et Dativo coniungantur. 
solidación del término "dativo posesivo", como a poner de manifiesto la relevancia de este tipo de dativos ${ }^{24}$, no sólo desde el punto de vista sincrónico sino también desde el diacrónico.

Uno de los primeros problemas que suscita el "dativo posesivo" es precisamente el de la pertinencia de tal denominación, que algunos autores, y en particular García Hernández 1992a, 1993, y sobre todo 1995b, han considerado con no poca razón inapropiada. Sea como fuere, el término sigue siendo moneda común en los tratados de sintaxis latina, pero también en estudios al respecto en las diferentes lenguas románicas (Sirbu-Dumitrescu 1989; Dumitrescu 1990, versión revisada y ampliada del anterior artículo; Delbecque y Lamiroy 1996-1998; Gutiérrez Ordóñez 1999).

Una de las cuestiones que más ha interesado a los latinistas en este punto ha sido el del estatus sintáctico de dicho dativo. Por tal motivo, se han estudiado las relaciones de similitud/complementariedad que existen entre esta construcción y la del verbo 'habeo + acusativo', tanto desde un punto de vista diacrónico (Meillet 1924a; Herman 1965; Veyrenc 1975; García Hernández 1993; Iso Echegoyen 1995), como sincrónico (Schenk 1892; Schunk 1900; Benveniste 1963; B. Löfstedt 1963; Serbat 1983; Lavency 1985; Rosén 1992; Joffre 1996). Con todo, el asunto capital ha sido la especificidad (o no) del dativo posesivo como valor autónomo.

La Gramática Funcional considera que las dos funciones semánticas que pueden dar cobijo al dativo son, por orden de importancia jerárquica, la de Receptor y la de Beneficiario (Dik $1978=1981$, p. 108). Bolkestein 1983, por su parte, entiende que conviene crear una tercera, la de Experimentador ("Experiencer") para explicar el valor semántico del dativo posesivo latino. Esta postura difiere de la sostenida por Maurel 1989, (citado en García Hernández 1992b, p. 329), para quien la diferencia entre "dativo posesivo" y "genitivo posesivo" reside en la estructura informativa, no en la semántica, de suerte que en la contrucción que nos ocupa el dativo representa "el ele-

24 Cabe señalar, además, que B. Lösfstedt cita muchos trabajos de índole gramatical sobre diversos autores concretos, Propercio, Lucilio, Lucrecio, Petronio, Celso, etc.; alguno de ellos aparece recogido en el Anexo II de nuestra Bibliografía, pero para referencias más detalladas de este tipo de estudios en el s. XIX nos remitimos a Landgraf 1903, pp. 88-96. Existen igualmente varias gramáticas latinas en las que se recogen trabajos que aluden esporádicamente a ejemplos de dativos; son de particular interés a este respecto las de Reisig 1888, Kühner-Stegmann 1912-1914²: t. II/2, y Hofmann-Szantyr 1972, t. II. 
mento conocido" ${ }^{25}$. Más recientemente García-Hernández 1992b, p. 330, ha terciado en esta disputa para señalar, en primer lugar, que «las diferencias pragmáticas y semánticas no son excluyentes», y en segundo lugar, que «la función de Experimentador ("Experiencer") que se asigna al dativo con sum no es distinta de la noción de "interés" o "destino" que conviene en general al dativo» (p. 331, n. 5). Más aún, este mismo autor (1992a, p. 68) en otro artículo titulado significativamente «El dativo con sum, ¿un dativo específico?», ha hecho notar que «la equiparación del dativo llamado 'posesivo' con otros especímenes como el simpatético, el agente, el datiuus iudicantis, etc. .... viene a revelar tanto la identidad básica de dativos aparentemente diferentes como que el dativo con sum es uso normal y corriente del ese caso, sin otra particularidad que la de ser regido por un verbo determinado» ${ }^{26}$.

Landgraf 1893, p. 40, habla del «Der sogen. Dativ statt des Genetivs (Dativus energeticus)». A propósito de dicho dativo (llamado también 'Dinamicus' y 'Sympatheticus'), escribe Landgraft (p. 41) un poco más adelante: «lassen sich also zwischen beiden Konstrucktionen keine historischen Untershiede festellen, so bieten sie mehr nur ein stilistisches Interesse; der Dativ mag mit Vorliebe vorangestellt sein ${ }^{27}$. Havers 1911, p. 2, por su parte,

25 Aunque curiosamente esta postura fue defendida en un trabajo anterior por Bolkestein 1980, p. 19ss.

26 En relación a estas palabras de García-Hernández conviene señalar que Landgraf 1893, p. 46, alaba la opinión de Rumpel y Hübschmann cuando señalan que desde un punto de vista gramatical las categorías de datiuus commodi y datiuus incommodi son innecesarias. No conviene olvidar, a su vez, que este mismo autor un poco más adelante (p. 48) se hace eco de la definición que Buttmann (no indica dónde, pero tal vez sea en su Griechische Grammatik de 1829) da del datiuus ethicus («leiseren Datiuus commodi»). Por último, dejaremos constancia expresa de la forma en que Landgraf (p. 69) desde una postura no localista imbrica el dativo local con el de finalidad: «zwischen der Bestimmung oder dem Zwecke einer Thätigkeit (dem inneren Ziele) und dem örtlichen (äuseren) Ziele einer Bewegung besteht eine enge Verandtschaft». No es preciso decir el gran interés que tiene comparar la forma en que dicho autor justifica estas transiciones con los argumentos que al respecto esgrimen, $p$. ej., Bennett 1910-1914, t. II, desde una postura localista, o Fay 1911 con su "doctrine of opposites". Cumple aquí recordar el artículo de Maurel 1982, donde plantea la necesidad de hacer en algunos casos un recorrido inverso, esto es, no su interpretación semántica, sino más bien las condiciones sintácticas que justifican su aparición.

27 Esta cita nos recuerda la valoración que hace Gildersleeve (de la que se hace eco E. Löfstedt 1928-1933, t. I, p. 168) a propósito de dativos tipo ministros bello, custos saluti, etc., «more sympathetic than the Gen.». Sería un ejercicio interesante comparar los ejemplos dobles dativo/genitivo que sobre autores clásicos ha recogido Heumann (algunos citados por Landgraf 1893, p. 41) y los genitivos que Vegecio al refundir la Mulomedicina de Quirón 
subraya «er ist subjektiver, wärmer und innerlicher als der Genetiv, der einfach objectiv ein Besitzverhältniss konstatiert». Tal vez sea ello lo que justifique, como hizo notar Landgraf 1893, p. 42, que el uso del dativo se extendiera enormemente entre los poetas, sobre todo a partir de Lucrecio.

Pasamos ahora a los giros preposicionales que entran en concurrencia con el dativo.

Hace ya algunos años Théoret 1982 escribió una extensa monografía de más de quinientas páginas titulada Les discours de Cicéron. La concurrence du tour casuel et du tour prépositionnel. Este trabajo, como el propio autor indica al principio de su obra, tiene como objetivo salir al paso de la tendencia que tienen las gramáticas latinas a considerar que el empleo de un caso solo o precedido de preposición resulta indiferente. Tras un minucioso estudio de las condiciones de aparición de los casos en solitario (acusativo, dativo y ablativo) y los precedidos de preposición llega Théoret a la conclusión de que en la mayor parte de los usos sí existe alguna diferencia entre ambas construcciones. Generalmente ésta se basa en que los usos con preposición expresan un "sens concret" y los casos solos un "sens abstrait". A veces los primeros expresan cosas inanimadas y los otros seres animados, pero esto sólo es un hecho secundario, como repite a menudo Théoret, quien de esta manera se muestra contrario a la communis opinio de las gramáticas tradicionales que tienden a establecer una relación directa entre una y otra circunstancia.

Conviene reseñar, por otra parte, que no faltan observaciones de mayor o menor calado acerca del papel que desempeñan las preposiciones en relación a los casos (p. ej., Pinkster 1972, p. 148 ss, y 1990 = 1995, pp. 84-86; Touratier 1978, pp. 148 ss.; Rubio $1989^{3}$, p. 153 ss.; Calboli 1983, p. 53 ss.; Moralejo 1986, pp. 321-323; Luraghi 1989; Echarte 1991a, 1998; Carvalho 1980b, 1996a).

Tal vez quien ha llevado más lejos en el terreno de la lingüística latina las consecuencias que se derivan de la interrelación entre casos y preposiciones haya sido Binkert $1970=1977$, p. 2 del Abstract, quien desde una perspectiva generativista sostiene que «all case constructions in Latin are transformations of underlying prepositonal phrases»; como es natural dicha

convirtió en dativos (varios de los cuales aparecen en E. Löftstedt 1928-1933, t. I, p. 182). Woodcock 1959, p. 46, a su vez, cree que el uso del dativo frente al genitivo implica «the existence of the thing possessed as not being previously known». 
conclusión afecta también al dativo latino, aunque sus palabras vayan en una dirección completamente opuesta a la communis doctrina al respecto: «the dative of indirect object, the dative used to express the goal of motion, the dative of possession, the dative of agent, the dative with special verbs like studeo, the dative with compound verbs, the dative with impersonal constructions like necesse est, and the dative with adjectives and nouns. All of these datives are derived from prepositional phraes which are introduced by one specific meaning class of prepositions» (pp. 2-3 del Abstract). Una lectura del análisis que Binkert hace del tibi inicial de frase que él asimila a lo que llama "English to-phrases" (pp. 288-289) nos hace sospechar que su método y sus conclusiones están muy mediadas por el inglés en tanto que lengua de origen desde la que están formuladas las hipótesis de su basamento teórico, y en tanto que lengua de destino por ser el conducto necesario por el que se accede a una supuesta "estructura profunda" 28 .

A pesar de las precedentes citas y observaciones, falta un trabajo genérico donde se haga una descripción de todos los elementos en cuestión y un análisis integrado de los mismos como conjunto de unidades interdependientes ${ }^{29}$. Sea como fuere, debemos tener presente que no a todos los latinistas les pasaron desapercibidas las sutiles diferencias que a veces separan unas construcciones de otras. Así, p. ej., ya Dubský 1929, p. 299, hizo la siguiente observación: «les écrivains latins, surtout à l'époque classique, avaient encore le sentiment d'une nuance entre les constructions mitto epistulam amico et mitto epistulam ad amicum ...: le datif simple exprime un rapport plus intime, plus étroit, de l'action au complément, tandis que le cas prépositionnel indique plutôt une certaine modification ... du sens primitif du verbe par rapport au complément». Recientemente Baños 1996 ha estudiado esta misma opo-

28 Nos resulta sorprendente que en la bibliografía final de esta Tesis Doctoral no aparezca citado ningún trabajo anterior específico relativo al tema en cuestión. Para una visión crítica del estudio de Binkert en relación con el modelo de Gramática de casos propuesto por Fillmore son de interés las observaciones formuladas por Calboli 1972, p. 268 ss.

29 No le falta razón a Torrego 1996, p. 214, cuando hace notar que «la sintaxis de los casos no puede estudiarse separadamente de la de los otros elementos, como SP, adverbios y oraciones subordinadas»; ahora bien, este programa maximalista no puede llevarse a efecto sin que antes se haya cubierto de manera satisfactoria el estadio intermedio por el que nosotros estamos abogando aquí. Recientemente Echarte 1998 ha publicado un trabajo con el atractivo título de «Preposiciones y casos en latín: propuesta de un sistema conjunto»; sin embargo, la propia extensión del artículo sólo le ha permitido plantear un acercamiento somero al problema. 
sición (litteras Neroni/ad Neronem mittere) y otras por el estilo (Baños 1998), de suerte que sus conclusiones constatan una diferente función semántica para cada una de las construcciones aludidas: el dativo indica el "receptor", y el giro preposicional el "destinatario".

Por otro lado, no conviene olvidar que también es posible un tercer tipo de relación entre ambas construcciones, a saber, la de que funcionen en distribución complementaria. Esto es precisamente lo que propone Torrego 1989, p. 615, para aduersus, contra, in + Ac. frente al Dativo cuando expresan la función semántica de Beneficiario: el Dativo se emplea cuando «el lexema del término regente es lo suficientemente concreto como para no permitir ambigüedad» (p. 613).

De todos los usos del dativo latino tal vez sea el llamado "dativo de dirección" el que más se preste a un análisis en estrecha relación con giros preposicionales. De hecho, esto viene sucediendo ya desde la Antigüedad, cuando los propios gramáticos romanos optaron por dar autonomía a este uso y llamarlo octauus casus (Murru 1978).

Conviene reseñar que aunque los ejemplos del dativo de direción no son muy numerosos, no se trata ni mucho menos - como parecen sugerir las gramáticas - de un grupo homogéneo. De hecho, Colucci 1981, el autor que mayor atención le ha prestado, ha puesto de manifiesto que varios de ellos son "dativi originari direzionalizzati", e incluso llega a postular que algunos son "ablativi e strumentali trasformati in dativi direzionali" ${ }^{30}$.

Tanto en la citada monografía de Colucci como en otros trabajos modernos a propósito del llamado 'dativo de dirección' (Bonelli 1983; Echarte 1994; Gutiérrez Galindo 1995) se insiste en que tal caso no recoge propiamente el valor de dirección como algo concreto, de suerte que el término con el que se le designa parece inapropiado ${ }^{31}$.

Hace ya muchos años que se puso de manifiesto (Schäfler 1884; Brenous $1895=1965$, p. 193 ss.) que el dativo del tipo it clamor caelo - tal vez el más emblemático de todos los dativos de dirección - ha de ser considerado como un helenismo y su uso es básicamente literario. Con todo, esta apre-

\footnotetext{
30 Recuérdese que ya Schroeter 1873, al que luego seguirían otros autores, interpretó algunos dativos de dirección latinos como antiguos locativos.

31 Echarte 1994, p. 239, indica que este dativo sólo recoge el "aspecto teleológico" del movimiento. Gutiérrez Galindo 1995, por su parte, ha hecho notar que el dativo conduce a una "subjetivización" tal del movimiento que éste ya no se presenta como siguiendo una línea continua en dirección a un lugar concreto, lo que permite obtener de él un alto rendimiento poético.
} 
ciación histórica no exonera a los los lingüístas posteriores de ofrecer una explciación sincrónica del fenómeno en latín.

Para un análisis moderno de las fuentes grecolatinas a propósito del octavus casus son de particular interés los trabajos de de Mauro 1965, Calboli 1972, pp. 105-113, Murru 1978, 1979a, 1979b y 1980a y Bonelli 1983.

Conviene tener presente que algunos usos latinos del dativo pueden deberse a la influencia del griego ${ }^{32}$. Los ejemplos más llamativos fueron sistematizados y estudiados por Brenous $1895=1965$, pp. 142-208, a saber: el dativo con verbos que expresan la idea de unión y hostilidad, idem con dativo, dativo con verbos pasivos ${ }^{33}$, el dativo de relación ${ }^{34}$, algunos dativos 'por atracción' y, por último, el ya citado dativo del tipo it clamor caelo.

Por último, citaremos sólo de pasada (pues la discusión a menudo va más allá de lo meramente sintáctico) la polémica que Lenchantin de Gubernatis 1911, 1914a; 1914b y Rasi 1914 mantuvieron en el Bolletino de Filologia

32 Sin duda que el terreno de los "helenismos sintácticos" es muy resbaladizo, por tal motivo conviene pisarlo con muchas cautelas, como hace, p. ej., Allen 1897 en su reseña al libro de Brenous, en la que no por casualidad menciona varios pasajes referidos al dativo. De hecho, E. Löfstedt $1959=1980$, p. 183, hace notar que, aunque en griego tardío y bizantino muchos verbos «si costruiscono con il dativo, ... ma non dovrebbe averlo influenzato se non in casi eccezionali. In parte questa "mania del dativo" (Krumbacher) reca un'impronta di artificialità». Cabe recordar, por otro lado, que algunas gramáticas en el apartado del dativo incluyen una sección dedicada a los usos debidos al influjo griego, como es el caso de KühnerStegmann 1912-1914², t. II/1, pp. 317-320; estos mismos autores (t. II/1, pp. 336-341) incluso dedican otra sección a los verbos que unas veces van con dativo y otras con otros casos; también son de cierto interés los asuntos, acompañados de numerosas referencias bibliográficas, que Reisig 1888, pp. 591-598, plantea al respecto. El giro virgiliano (Ge. III 193) laboranti similis y otras construcciones similares son debidos a la influencia griega, según ha puesto de manifiesto Traina 1969, pp. 71-78, en un breve trabajo que, a su vez, fue prontamente corregido y aumentado por un aún más breve artículo de Lunelli 1969, pp. 341-342.

33 Este asunto había sido ya tratado con un cierto detalle por Tillmann 1881. Sobre el dativo agente indoeuropeo publicó hace algún tiempo Green 1913 una monografía donde minimiza el influjo del griego en el empleo latino de dicha construcción, toda vez que, según él, se trata más bien de una herencia indoeuropea y sólo en algunos casos puntuales podría justificarse dicha dependencia. En su breve pero denso artículo titulado «The Dative of the agent in Horace's Odes», ninguna consideración hace Richardson 1936 al respecto.

34 Hace tiempo que este tipo de dativo fue objeto de un breve pero denso estudio realizado por Hauser 1878, aunque en él nada se diga acerca de un posible influjo del griego, salvo breves alusiones en alguna nota a pie de página. Este trabajo aparece citado y ampliamente comentado en un artículo de Landgraf 1893, p. 50 ss. Wölfflin 1881, por su parte, escribió unas breves notas sobre la cronología del dativo, «qui dicitur iudicantis». 
Classica a propósito del uso del verbo pendère con un presunto "dativo de contacto", siendo así que dicho verbo suele ir acompañado de un sintagma preposicional.

\subsection{El datiuus comparationis}

El datiuus comparationis es uno de los usos del dativo que aparece recogido con menos frecuencia en los tratados gramaticales latinos, hasta el punto de que a veces ni siquiera lo encontramos en trabajos donde se estudia con gran detalle el sistema casual de la lengua del Lacio, así p. ej. en el de Bennett 1910-1914, t. II. Más aún, en una Gramática de tanto calado como la de Hofmann-Szantyr 1972, t. II, pp. 113-114, no sólo se considera que «der sog. Dativus comp. ist sehr beschränkten Unfangs und hat seinen Ausgangpunk in nulli ... inferior», sino que las breves consideraciones que se hacen al respecto aparecen insertadas en la sección dedicada genéricamente al Ablativo ${ }^{35}$.

Con todo, ya a principios del s. XX encontramos algún breve estudio sobre este asunto. Entre ellos está el de von Geisau 1914, pp. 222-223, donde se someten a consideración cuatro ejemplos concretos de dicho uso; algunos de ellos citados y discutidos ya anteriormente por Wölfflin 1889, pp. 466-467, 1892, p. 117, a propósito del genitiuus comparationis y del ablatiuus comparationis, respectivamente. El restringido empleo que tiene este uso del dativo justifica algunos problemas de transmisión textual a que ha dado origen, como ponen de manifiesto las breves consideraciones que al respecto publicó Elg 1947.

Algunos estudiosos Reisig 1888, p. 616 ss., creen que en algunos usos del dativo que nos ocupa puede detectarse el influjo del griego, que primero se haría patente en los ejemplos que nos ofrecen los poetas (como p. ej. Horacio), y más tarde en los prosistas (Salustio, etc.).

Sobre su pervivencia comenta Miăescu 1978, p. 5: «le datif comparativ est rare dans le latin tardif: il n'apparaît qu'une seule fois chez Auxentius, sans constituer un trait spécifique de la latinité balkanique».

35 Peor trato incluso recibe, p. ej., en la Gramática de Kühner-Stegmann 1912-1914 ², t. II/2, pp. 468-469, que dentro de la sección dedicada a las «Vergleichende Adverbialsätze der Qualität etc.» hace unas observaciones bajo el rótulo «Statt des Ablat. comparationis begegnen zuweilen auch andere Ausdruckweisen», y entre ellas está «der Komparativ mit Dativ oder Genetiv sowie mit $a b$ oder $d e »$. Sea como fuere, debemos citar en este punto el vetusto trabajo de Müller 1836 sobre los adjetivos que se construyen bien con genitivo bien con dativo. 


\subsection{El doble dativo y construcciones próximas}

La existencia de dos complementos en el mismo caso, pero no como aposición uno del otro, es susceptible a priori de diferentes interpretaciones. En latín existe el llamado doble dativo, de compleja interpretación y que no ha logrado sustraerse a la polémica de los estudiosos. Por ello no es de extrañar que se haya generado una cierta literatura al respecto, particularmente en los últimos tiempos y al socaire de los presupuestos teóricos de las nuevas corrientes lingüísticas.

No obstante, es justo que citemos en primer lugar el artículo de Haudry 1968, titulado «Les emplois doubles du datif et la fonction du datif indoeuropéen», en el que propone que se invierta el proceso habitual de anális del dativo las lenguas indoeuropeas y se examinen «les emplois simples à la lumièree du tour double» (p. 149). El resultado al que conduce este enfoque de Haudry (pp. 158-159) es que «toutes les valerus 'prospectives', éventuelles, finales, consécutives, etc. ... son sous-tendues par un élément ... implicite ... effect de la réduction, qui constitue la fonction centrale du datif». La anterior explicación historicista, a pesar de su interés intrínseco, apenas sí ha sido tenida en cuenta en los análisis sincrónicos posteriores del doble dativo en latín.

Sobre la dificultad que plantea el análisis sintáctico de los elementos que conforman la construcción que nos ocupa da idea el hecho de que un autor como Pinkster $1990=1995$, p. 28 , se muestre vacilante al respecto, hasta el punto de que en una frase como erat odio Hannibal Romanis considera al dativo de finalidad como un "complemento del sujeto" y al dativo de persona como un complemento-argumento, pero unas páginas más adelante (p. 50) incluye el datiuus finalis en la periferia, aunque a renglón seguido apostille (p. 51): «es discutible si el dativo predicativo puede considerarse omisible. En mi opinión es obligatorio».

Las posibilidades de análisis del doble dativo latino son básicamente las siguientes:

a ) Que ambos dependan por igual de un mismo predicado. Esta postura es la que subyace a muchos manuales de gramática (p. ej., Bassols 1956, t. I, p. 113).

b) Que cada uno de los dativos se encuentre en un nivel sintáctico distinto de la predicación. De esta opinión es Baños 1995, para quien el dativo de persona (Beneficiario) depende del dativo de cosa (Finali- 
dad); esta solución sería la contraria a la que sugiere Haudry 1968 para el védico ${ }^{36}$.

c) Que el dativo de finalidad complemente al predicado sum + dat. posesivo (Suárez 1992).

d) Que el dativo de persona funcione como un complemento de frase, en un nivel sintáctico superior al del dativo de finalidad (Mellado, en Baños 1995, p. 20, n. 17).

En un trabajo reciente a propósito de la construcción latina dono dare Suárez 1992, p. 40, ha sugerido que debe interpretarse como "el resultado del desarrollo de un tipo de doble dativo". Este mismo autor (pp. 39-40) entiende que el dativo dono del giro que nos ocupa no es más que un dativo "predicativo" (en el sentido de "finalidad", e incluso "interés").

El término "predicativo", que ha quedado muy relegado por los lingüistas actuales, fue bastante empleado para hacer referencia a un tipo de dativo por los latinistas a partir de las primeras décadas del s. XX; por tal motivo encontramos trabajos específicos en los que dicho término aparece ya aludido en el propio título, como ocurren en Baxter 1925, 1934, Souter 1925 o, para el latín medieval, Werner 1937. No obstante, es preciso tener en cuenta que tales trabajos se limitan a completar la famosa lista de "predicative datives" que había elaborado unos años antes Roby 1889-1896, t. II, pp. 51-61.

Citaremos a continuación las conclusiones más relevantes de un breve trabajo de Riemann 1890, p. 67, en el que se critican algunas opiniones bastante extendidas en la época: $\ll 1^{\circ}$ Kühner se trompe, quand il dit que le datif est le plus souvent accompagné d'un adjectif .... $2^{\circ}$ On ne peut pas ajouter au datif du substantif un adjectif quelconque, mais seulement un adjectif marquant une idée de quatité ... dans l'expression familière 'esse frugi bo$n a e^{\prime} . .$. on ne pourrait plus (commen le font Dräger, Kühner, Schmalz) considerer frugi bonae comme un datif $\gg$.

Sobre la evolución en latín del dativo predicativo, en particular, y del doble dativo, en general, exisisten dos trabajos publicados también en esta época y en los que se muestran opiniones divergentes: la de Compernass 1914, para quien el latín vulgar desconoce el doble dativo, y la de Schmalz 1916, que presenta datos y argumentos en contra de Compernass.

36 En otro trabajo Baños (996, p. 230, a propósito del dativo de persona de un ejemplo como symphoniacos homines sex cuidam amico suo Romam muneri missit Cic., Verr. V 64), se pregunta «si no depende de muneri más que de misit». 


\subsection{El dativo de dirección}

El progresivo rechazo que el el siglo XX fueron teniendo las teorías casuales localistas que tanto auge tuvieron en la centuria anterior no impidió a los estudiosos aceptar la existencia de dativos latinos con valor directivo claro. Tal vez sea E. Löfstedt 1928-1933, t. I, p. 149 ss., quien con mejor tino critica los excesos de los localistas sin caer él mismo en la negación completa y absoluta de la existencia de un dativo de dirección en latín. No faltarán, sin embargo, autores que rechacen la idea de que el dativo latino pueda significar dirección. Esta idea se encuentra ya expresada genéricamente en autores como Meillet o Pisani, pero será Colucci 1981 quien la lleve a sus últimos extremos. A propósito de la monografía de dicho autor puede leerse el análisis crítico realizado por Bonelli 1983.

Los gramáticos latinos, de ello ofrece una eficaz síntesis Calboli 1972, t. I, pp. 110-113, hablan con frecuencia de un octauus casus, que ejemplifican con la conocida frase virgiliana it clamor caelum, y hablan de un datiuum sine praepositione que se utiliza en lugar de un accusatiuum cum praepositione. Murru 1978, 1979a ha hecho un detenido estudio histórico sobre los avatares sufridos por el octauus casus.

El sentido directivo está, por tanto, claro; ahora bien, no es tan evidente (como ha hecho notar Calboli 1972, t. I, p. 110) si para ellos «l'octauus casus sia un casus o una elocutio». Para comprender mejor dicho problema es preciso tener en cuenta que tal disyuntiva se presentaba también a porpósito del llamado septimus casus. De ello dan cuenta diversos trabajos modernos al respecto, entre los que está, p. ej. el de Iso 1975. Dicho estudioso hace la siguiente observación, no carente del todo de interés (p 46): «no está claro ... si en el caso de una coincidencia formal de dos casos (el dativo y nuestro ablativo) se piensa ... en que el dativo es el caso más antiguo y de él se deriva el otro».

Tal estado de cosas explica que en las últimas décadas diversos latinistas se interesaran por el llamado dativo de dirección latino (octauus casus) y llegaran incluso a ponerlo en relación con la teoría fillmoreana de la Gramática de casos (Calboli 1972, t. I, p. 110, Murru 1978, Bonelli 1983), o bien que, como señala Serbat 1992, p. 71, su estudio pueda contribuir «à un débat toujours actuel».

Habría que recordar que ya Laborderie 1934, p. 279, hizo notar que «de l'idée d'intérêt se passe facilement à celle de destination, que bien peu de distance separe de celle de direction». 


\subsection{El dativo latino en otras teorías}

Una de las teorías en las que el dativo ha recibido una importante investigación ha sido en la Gramática de casos. Fillmore $1971=1976$, p. 181, el más eximio representate de esta tendencia, en una versión renovada de su propuesta inicial, pensó que en el dativo se neutralizaban tres casos subyacentes: Experimentador, Objeto y Meta ${ }^{37}$. Para lo que hace al latín, Harris 1975, p. 183, fue más lejos y separó del caso Meta el caso Recipiente; en el latín arcaico el primero representaría al acusativo y el otro al dativo, y en latín vulgar y en romance ambos se sincretizan. Murru 1979a, p. 295, por su parte, extendió todavía más el abanico de posibilidades hasta el punto de proponer que en el dativo latino se neutralizarían el Experimentador, el Paciente, el Objetivo, el Origen, la Meta y el Locativo.

De hecho, quienes han intentado adaptar la teoría en cuestión al latín han ampliado considerablemente el número de "casos profundos"; así, Baldi 1973, p. 53, habla de 10, Harris 1975 de (sólo) 3, y Murru 1979a de 11, aunque renuncia expresamente a otros cuatro (Contraagente, Tiempo, Causa y Benefactivo).

Tal proliferación incontrolada de casos ha suscitado numerosos rece$\operatorname{los}^{38}$. En diferentes momentos ha definido Fillmore 1968, $1971=1976$ los casos como "relaciones sintáctico-semánticas". No obstante, como ha hecho notar Newmeyer $1980=1982$, p. 184, en el sistema fillmoriano «eran demasiado someras para satisfacer a la sintaxis abstracta, y mucho menos a la

37 La primera versión fue severamente criticada, entre otros, por Harris 1975, p. 184: «the 1968 definition of Dative given above [sc. "the case af the animate being affected by the state or action identified by the verb"] is ipso facto unacceptable. Actually, the Dative case itself is now abandoned, or rather re-analised». No debemos olvidar, por lo demás, que la Gramática Generativa de (pen-)última hornada se sirve de una parecida división; así, Fernández Lagunilla et al. 1995, pp. 288-290, describen el Objeto Indirecto en español sirviéndose de los tipos: OImeta, OIexp. y OIbenefactivo. Convendría recordar aquí que Pottier $1974=$ 1977, p. 142, desde una perspectiva muy personal, habla de «once casos conceptuales», aunque «su número nada tiene que ver con el número de casos en las lenguas naturales»; por ello,

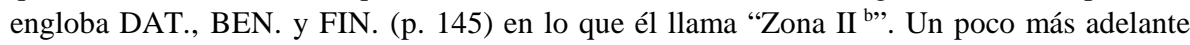
(pp. 150-151), al hablar del dativo dativo, deja la frase inacabada: «El dativo evoca finalidad, destino ... ».

38 Para visiones críticas generales del problema son de interés, entre otros, Cook $1970=$ = 1979, pp. 1-15, Fletcher 1971, Calboli 1972, p. 221 ss., Mellema 1974, Pak 1974, Arutjunova 1975 , Serbat $1981=1988$, pp. 218-239, Newmeyer $1980=1982$, pp. 181-186, García Hernández 1986 o Álvarez Benito 1992. 
semántica generativa». Tal vez por ello las críticas le llovieron desde todas las partes, desde dentro y desde fuera de las las filas generativistas ${ }^{39}$.

Haremos referencia en lo que sigue a los escasos estudios sobre el sistema casual latino inspirados en teorías generativo-transformatorias.

Lakoff 1968, p. 99, en el capítulo tercero su su monografía Abstract Syntax and Latin Complementation comenta: «the same rules may apply to deep structures in Latin as apply to those in English»; y unas líneas más adelante (p. 100): «about the morphological components of the language ... there is no indication for any of the rules of English complementation that it must not apply in Latin».

Lakoff (p. 90-95) se refiere en varias ocasiones al dativo latino. Acerca de los sintagmas licet me ire y licet eam opina (pp. 91-92) que «there is probably a dative present in the deep structures ... This is the "unspecified person" or "someone" usually deleted both in Latin and in English»; tal suposición le lleva a la siguiente conjetura: «thus, we derive al cases of licet from an underlying *liceor».

Las consideraciones anteriores nos llevan a preguntarnos en qué medida la lengua que sirve de referencia (inglés) y el propio método de trabajo empleado condicionan los resultados obtenidos a propósito de los hechos lati$\operatorname{nos}^{40}$.

Pasamos ahora a comentar el estudio de Binkert $1970=1977$ titulado Case and prepositional constructions in a Tranformational Grammar of Classical Latin. Piensa este autor norteamericano que el dativo latino que es un caso "semántico". Considera, además, que su valor semántico se encuentra ya en la estrcutrua profunda, tesis que ha sido criticada por Calboli 1972, t. I, p. 293 ss.

Por lo que hace a la teoría de Binkert $1970=1977$, p. 169 , conviene recordar que sus dos tesis principales al respecto son, por un lado, que «the nominative with habere, the dative with esse, and the dative dare, all have the same source», y, por otro, que «that source is a prepositional phrase introducted by $a d$, i.e., an afferential prepositional phrase» ${ }^{41}$.

39 Sobre este asunto hemos hablado en Gutiérrez Galindo (en prensa).

40 El libro de Lakoff fue objeto de una larga reseña (entendemos que bastante benévola) por parte del latinista galo Touratier 1969. Por lo demás, en ella se pasan por alto los no muy numerosos pasajes en que Lakoff alude al dativo (latino).

41 Como hace notar Calboli 1972, p. 273, n. 20, alguno de los rasgos semánticos utiliza- 
Pepicello 1977, p. 475, por su parte, escribió un breve artículo sobre las construcciones de acusativo/dativo con infinitivo. Para explicarlas se defiende la conveniencia de aplicar un "raising analysis", de suerte que «the apparent motivation for the use of one construction over the other is the semantic focus of the sentence», esto es, «a dative-infinitive focusses on the indirect object of a given verb».

Sánchez Salor 1994, p. 114, en un trabajo sobre las construcciones pasivas con tres actantes, donde el dativo tiene un papel importante, comenta que en tales contextos los casos sólo se pueden explicar «desde un análisis en que se tenga en cuenta el nivel semántico».

Sobre el verdadero alcance de las aportaciones de la Gramática Generativa al problema de los casos citaremos la opinión poco sospechosa del eminente latinista italiano Calboli 1983, p. 63, autorizada por ser un gran conocedor tanto de la lingüística europea como de la Gramática generativa: «la grammatica trasformazionale è sostanzialmente insuficiente a chiarire l'aspetto fondamentale dei casi, aspetto che consiste in un raporto semantico tra nomi e verbi nell'articolazione sintattica della frase».

Daremos en lo que sigue unas breves pinceladas sobre las tesis psicologizantes de Guillaume desarrolladas en lo que hace al latín por de Carvalho ${ }^{42}$. Dicha teoría tiene un importante componente semanticista que justifica el interés de Carvalho 1985a, t. II, p. 716 ss., por las tesis de Fillmore, bien sea para criticarlas, bien sea para retomarlas en alguna medida. El latinista galo (t. II, p. 836) define el dativo de la lengua del Lacio como sigue: «la représentation, portée par le cas datif, d'un NON-PROTAGONISTE "inactuel ultérieur", supposant, "derrière lui", l'existence d'un présent délocuté, et en recueillement durablement les apports positifs ou négatifs - dépendant, par conséquent, du dit présent délocuté; le datif est, en quelque sorte, l'homologue, dans le plan nominal du futur». Un poco más adelante comenta Carvalho (t. II, pp. 844-845) que el valor de "inactuel ultérieur" explica los diferentes usos del dativo, desde el posesivo, pasando por el agente o el de atribución hasta llegar al de dirección ${ }^{43}$; más aún, en su opinión (t. II, p.

dos por Binkert en las clasificación de los casos latinos recuerdan a los criterios empleados por Hjelmsev, que, a su vez, pueden ponerse en relación con los que los gramáticos bizantinos Máximo Planudes y Teodoro de Gaza justifican su teoría casual localista.

42 Sobre todo en su monografía de más de mil páginas titulada Nom et déclinaison. Recherches morpho-syntaxiques sur le mode de représentation du nom en latin (Carvalho 1985).

${ }^{43}$ Sobre el dativo en posición inical opina (t. II, p. 514) que «a plus de chances de s'ap- 
844), «permet de comprendre l'absence de ce cas dans certains contextes où un raisonnement sommaire, par tradition, le ferait attendre».

Serbat ha sido seguramente el latinista moderno que más páginas ha escrito sobre el dativo latino. Aparte de aquellas que de manera más o menos genérica le haya podido dedicar en estudios generales como p. ej. sus Casos y funciones (Serbat $1981=1988$ ), dicho autor ha sacado a la luz varios trabajos específicos al respecto (Serbat 1989b, 1990, 1996a, 1996b), todos ellos de gran interés, aunque tal vez sea el último de ellos, titulado «Essai de définition du datif latin», el que mayor interés tenga desde el punto de vista teórico. En efecto, el autor ofrece en las once páginas que ocupa el trabajo aludido una visión destilada de las teorías y opiniones que ha sostenido en sus estudios anteriores, particularmente en las ciento cincuenta páginas de su Grammaire fondamentale du latin (Serbat 1996a) que ha necesitado para tratar de manera minuciosa los numerosos problemas que conlleva el análisis del dativo en latín.

Tres son las preguntas que el latinista galo entiende que deben plantearse para definir adecuadamente un caso (Serbat 1996b, p. 154): a) «quelle est sa position dans la charpente phrastique?»; b) «quel signifié véhicule la marque casuelle?»; y c) «quelle situation ocupe-t-il dans l'ensemble des morphèmes signalant une fontion nominale, c'est-à-dire, cas et prépositions?».

A la primera de ellas responde en los siguientes términos (p. 155): «Il partage néanmoins la propriété syntaxique de terme second avec tous les cas obliques, y compris l'accusatif». En lo que concierne a la respuesta a la segunda cuestión se da la circunstancia de que Serbat (pp. 155-156) acepta la dualidad propuesta, entre otros por Fugier, de distinguir entre "bénéficiaire" y "destinataire", y a la vez encontrar para el dativo latino «une valeur propre présente dans toutes les situations contextuelles»; tal desiderátum se cumple en lo que él llama "repère de visée" (que en ocasiones glosa como "pôle d'attraction"), de suerte que tal complementariedad entre lo que atrae y lo que es atraído se da prototípicamente en la secuencia dare nobis (p. 158), que él esquematiza como sigue (p. 156): dare $[\bullet \leftarrow]$ nobis $[\bullet \leftarrow]$, donde «la flèche représente le signifié de la désinence, et le point le thème du nominal» ${ }^{44}$.

parenter à un "datif d'intérêt" qu'à un "datif d'attribution"»; un poco más adelante reformula las palabras anteriores en los siguientes términos (t. II, p. 516), «pour adopter une aproche plus "moderne", plus "syntaxique" et, certainement aussi, plus adéquate: un non au datif en position initiale serait à interpréter moins comme un "complément" que comme un "sujet second".

44 Por su parte, Palmer $1954=1988^{2}$, p. 293 , que define el dativo latino de una manera 
En lo referente a la tercera cuestión, por último, Serbat (p. 164) responde: «Les tours les plus proches, avec lesquelles il entre en concurrence sont les syntagmes prépositionnels latifs (in + Ac; $a d$ ). ... Mais cette éviction ne doit pas conduire à croire que le $\mathrm{D}$ aurait été "directif" à la manière de $a d$ ». Los límites entre una y otra construcción, que el propio Serbat reconoce a veces como tenues (p. 164) han sido objeto en las últimas décadas de estudios detallados; son de interés los trabajos de Baños (1996, 1998), Cabrillana (1997a, 1997b), Colucci (1981), Echarte (1991a, 1994, 1998), Gutiérrez Galindo (1995), Théoret (1982), Torrego (1989).

Hay otros dos aspectos, a nuestro juicio de gran interés para una recta comprensión del dativo latino, sobre los que Serbat en todos los trabajos al respecto citados más arriba hace varias veces hincapié.

Por un lado, insiste en que el uso del dativo en lugar de otra expresión funcionalmente equivalente resulta mucho más expresivo. Así, p. ej., a propósito del giro virgiliano se euadere pugnae escribe (1996b, p. 161): «s'il avait écrit e pugna, ... il aurait été plus clair, mais beaucoup moins expressif».

El otro aspecto en el que incide a menudo el latinista galo, sobre todo al tratar del dativo llamado simpatético y del doble dativo, es lo que él llama "la dépendence du Datif" (particular interés tienen, p. ej., la líneas que dedica al respecto en 1996, pp. 564-566). Las dificultades de este problema también han sido puestas sutilmente de manifiesto por otros autores; así, las acotaciones que encontramos en Baños (1996) sobre este asunto son un buen exponente de ello.

\subsection{El dativo latino en la perspectiva tipológica}

Aunque la Gramática latina ha sido durante muchos siglos sinónimo de Gramática, son muchos los aspectos de la sintaxis del latín que están aún pendientes de un análisis tipológico que los relacione y compare con los datos que ofrecen otras lenguas o familias de lenguas para de esta manera poder definir su posición relativa en el espectro de realizaciones posibles. Sea como fuere, sería injusto olvidar que sí existe algún trabajo de este tipo acerca de las cuestiones que aquí nos vienen ocupando ${ }^{45}$.

más genérica ("la persona designada está implicada o afectada por el acontecimiento o estado de cosas al que el verbo o la expresión verbal se refieren"), lo representa como sigue: $-\bullet>$.

45 La brevedad no resta interés al trabajo introductorio de Lehmann 1979 titulado «Zur typologie der Lateinischen». 
La única aproximación tipológica acerca del sistema casual latino en su conjunto que conocemos es la que presentó hace algunos años Lehmann (1985) en su trabajo titulado «Latin case relations in typological perspective». Dicho autor concibe un caso - y en ello coincide con Fillmore - como «a semantically based notion whose structural correlates may vary» (p. 82). Con un criterio esperable y acorde con sus intenciones hace notar Lehmann (p. 84) al principio de su estudio que no todas la formas posibles (siete en total) de dependencia para una $\mathrm{N}<$ oun $>\mathrm{P}<$ hrase $>$ se documentan en latín. El principio general al que responden las predicciones tipológicas aparece enunciado en los siguientes términos (p. 93): «if, in a given language, a given case relation is marked by a given means, all the case relations to its left will be marked by means of equal or greater morphological substance and autonomy, and all the case relations to its right will be marked by means of equal or lesser morphological substance and autonomy». En lo que hace al dativo latino dicho principio tiene dos posibles repercusiones que Lehmann (p. 92) sintetiza como sigue:

i Adessive > allative: ... Latin ad

ii Allative > dative: Lat.- Rom. ad ...

A pesar del interés intrínseco que tienen las consideraciones tipológicas realizadas por Lehmann, lo cierto es que no debe olvidarse que, como subraya Herslund 1988, p. 313, el Objeto Indirecto ha sido «longtemps traitée en parent pauvre». Tal estado de cosas es preciso tenerlo en cuenta a la hora de hacer valoraciones relativas a los estudios tipológicos porque éstos sólo pueden alcanzar su pleno desarrollo cuando los estudios específicos sobre un asunto concreto han alcanzado un grado importante de madurez en diferentes lenguas. Si tenemos en cuenta que esta última circunstancia sólo en los últimos tiempos se viene haciendo realidad en lo que concierne al dativo, se comprenderá que los estudios tipológicos al respecto todavía estén en una fase incipiente. Por otro lado, las características gramaticales inherentes a la propia dativdad parece que dificultan aún más dicha tarea. En las conclusiones de un reciente trabajo a propósito del dativo en latín y en neerlandés van Langendonck 1996-1998, t. II, p. 255, señala que «it does not look plausible to set up one abstract meaning of "dativity"»; un poco más adelante hace este mismo estudioso (t. II, p. 256) la siguiente acotación: «the semantic roles figuring in the dative/IO configurations are more likely to have a certain universal validity, but much more research remains to be done». El problema de fondo que subyace al planteamiento universalista de la datividad es 
que, como han hecho notar algunos lingüistas (p. ej., Blake 1994), suele llamarse "dativo" a todo complemento importante no argumento (main noncore case). El resultado empírico de tal práctica es que la datividad es más bien un "universal de las lenguas indoeuropeas", si es que podemos dar por bueno este concepto (Langendonck 1996-1998, t. II, p. 256), que parece encerrar un cierta contradicción en los términos ${ }^{46}$.

Convendría tener presente también que para la Gramática de casos (Fillmore 1968 , p. 24), «the case notions comprise a set of universal ... concepts which identify certain types of judgements human beings are capable of making about the events that are going on around them». Sea como fuere, sobre las críticas que dicha teoría ha recibido ya hemos dado cuenta en $\S 3.5$.

Por otro lado, un aspecto en común que suelen tener las teorías con una cierta orientación universalista es su rechazo a la interpretación local del valor básico que debía tener el dativo indoeuropeo; este es el caso, p. ej., de van Langendonck 1996-1998, t. II, pp. 252-253, o de Harris 1975, p. 188; éste último estudioso argumenta (Palmer $1954=1988^{2}$, p. 293), entre otras cosas, que sólo una doceava parte de los nombres y pronombres latinos que aparcen en dativo se refieren a cosas.

Un aspecto concreto del dativo latino que ha suscitado un cierto interés desde la perspectiva tipológica ha sido el concerniente al orden de palabras (Rivero García 1998, p. 48).

En un trabajo de 1973 Blansitt postulaba que en cualquier lengua el orden dominante para cláusulas unitrasivitvas debiera ser aplicable a las cláusulas bitransitivas. Dos años más tarde Sedlak confirmaba dicha propuesta, y también la teoría de que las lenguas con un orden dominante SOV pueden tener como órdenes bitransitivos SDOV, SODV, SDOV/SODV y SOVD.

Elerick 1990, que en un trabajo anterior ya había postulado para el latín un orden SOV (Elerick 1989), se propuso dar la vuelta a las tesis mantenidas por Blansit y Sedlak para comprobar que las lenguas «which have the bitransitive order SDVO, SODV, or SOVD have SOV as the dominant order in the unitransitive clause» (p. 2). El estudio de Elerick está aplicado al latín y

46 Tal vez donde encontremos más consideraciones de índole tipológica sobre la datividad sea en Givón 1984-1990, en particular t. I, pp. 762-763; t. II, pp. 114-127, 139-145; no obstante, no hemos encontrado ningún ejemplo tomado del latín. Para un análisis de la datividad en una lengua no indoeuropea en la que no existe propiamente un caso dativo nos parece de particular interés el trabajo de Tuggy 1996-1998: t. I, pp. 407-452, titulado «Dative-like constructions in Orizaba Nahuatl». 
los datos que maneja están sacados de un corpus limitado de obras ciceronianas, en concreto de los discursos Pro Flacco y Pro Caecina, según indica el propio autor, que sintetiza en los siguientes términos su principal conclusión: «the Latin of Cicero has a default order, not a preferred but a dominant order, for unitransitive and bitransitive clauses. This variety of Latin is SOV/SDOV and is not a close call» (p. 16).

Cabrillana 1994 ha realizado interesantes observaciones tanto sobre el alcance de las tesis de Elerick como sobre la validez del método por él empleado, en particular por trabajar con un corpus muy limitado. De hecho, Cabrillana (p. 446) llega a decir que «no parece que el alcance de la inversión de implicaciones de la hipótesis de Blansitt tenga un fundamente suficientemente sólido».

Digamos, por último, que en ninguno de los trabajos de orientación tipológica citados a propósito del dativo latino ni en otros que sobre el orden de palabras han escrito los autores en cuestión (Elerick 1994; Cabrillana 1993, 1994) se hace referencia a la carga de énfasis que a menudo lleva el dativo latino, asunto en el que con frecuencia incide Serbat, como hemos recordado un poco más arriba.

\section{Observación final}

Una última observación queremos hacer. Tal vez sea en el campo de la epigrafía latina donde el uso del dativo esté más extendido y donde su rendimiento sea más notable, toda vez que es en las inscripciones donde este caso cobra particular relevancia, a veces incluso por partida doble. Sin embargo, a pesar de tratarse de un terreno especialmente privilegiado para su estudio, ni gramáticos ni epigrafistas han emprendido la tarea de llevar a cabo un estudio sistemático del dativo latino en las inscripciones, lo que no impide que unos y otros hagan a menudo interesantes observaciones sueltas al respecto $^{47}$. De hecho, ya un autor como Havers 1911, pp. 226-227, en una mo

47 Tampoco se ha hecho un estudio sistemático sobre el dativo en los autores latinos tardíos y medievales. Con todo, mencionaremos - sin afán de ser exhaustivos - algunos trabajos al respecto donde se ofrecen de manera más o menos esporádica acotaciones que pueden ayudar a comprender mejor a Laborderie 1934, p. 279 cuando comenta que dentro de la declinación latina el dativo «était un cas faible»: Bastardas 1953, §§ 9, 21, 28, 41, 42, sobre cartularios españoles de los siglos VIII al XI; Mohrmann 1961, t. I, p. 430; t. II, p. 330; 1965, t. III, pp. 65, 119-120, 205, sobre algunos autores cristianos de primera época; Bonnet $1890=$ 
nografía sobre la sintaxis de los casos en indoeuropeo dedicó un breve apartado a las inscripciones latinas.

Serbat 1996, t. I, p. 436, por su parte, ya se percató de la importancia que para el estudio general del caso en cuestión tienen las formas de dativo aisladas que encontramos a menudo en las inscripciones a manera de dedicatorias, etc. También en Hofmann-Szantyr 1972, t. II, p. 86, aparece citado el siguiente ejemplo sacado del CIL (XIII 2483) que merecería un análisis más en profundidad: hic requiescunt membra ad duus fratres Gallo et Fidencio.

Carnoy $\left(1906^{2}\right.$, p. 270), por su parte, ya hizo notar que algunos usos de "datif pour accusatif" (tipo ingredi paradidi januae), o de "datif pour in + ablatif" (tipo huic tumulo jacens) están próximos a otros similares empleados por Gregorio de Tours. No menos interesantes son los datos que arrojan al respecto las inscripciones encontradas en la Galia (Pirson 1901, pp. 173175, 191 ss.), en la Romania oriental, como han puesto de manifiesto, entre otros, Skok 1934, pp. 453-454, Giese 1952, Herman 1965, o en África (Poukens 1912). Konjetzny (1908 p. 315), por su parte, ofrece datos interesantes al respecto sacados del vol. VI del CIL. Significativos son igualmente los ejemplos de usos de genitivos por dativos en inscripciones que O. Prinz ofrece en el ThLL (VIII 683.54-73), circunstancia que también se documenta en inscripticones griegas (Petzl 1981, p. 106).

Aunque parezca sorprendente, a menudo se producen interpretaciones erróneas de formas de dativo en inscripciones epigráficas a causa de un deficiente análisis del contexto sintáctico. Así, por poner un ejemplo, del Hoyo 2001, p. 37, n. 13, en un reciente trabajo a propósito del Carmen epigraphicum de Pomponio muestra de forma convincente la necesidad de corregir una de dichas lecturas equivocadas.

1968, pp. 536-548, sobre Gregorio de Tours; Schrijnen y Mohrmann 1936-1937, t. I, p. 103 ss.; y, en especial, Romeo 1978 sobre Cipriano; Haverling 1988, pp. 221-22, acerca de Símaco; Svennung 1935, pp. 202-206, 220-226, 635, sobre Palladio y otros autores técnicos tardíos; Pérez González 1985, pp. 136-137, sobre los documentos de la cancillería castellana (años 1158-1214); Velázquez Soriano 1989, p. 433, en torno a las pizarras visigodas; Díaz y Díaz 1965, pp. 74-76, para el latín de la liturgia hispánica; Riesco Chueca 1995, pp. xliiixliv, sobre el Pasionario hispánico; González Muñoz 1996, pp. 151-153, 161-162, acerca de Álbaro de Córdoba; García Sanchidrián 1998 sobre Braulio de Zaragoza. 


\section{REPERTORIO BIBLIOGRÁFICO}

Como necesario apéndice y complemento de este trabajo, ofrecemos, finalmente, un repertorio bibliográfico, que creemos exhaustivo y actualizado, de los estudios mencionados, dividiéndolo en dos partes: en la primera recogemos los estudios específicamente dedicados al dativo latino, ordenados cronológicamente; en la segunda, los que abordan esta materia sin centrarse exclusiva o principalmente en ella.

\section{BIBLIOGRAFÍA ESPECÍFICA}

Müller, [?], 1836, Quaestio grammatica de Adiectivis quae cum utroque casu et Genitivo et Dativo coniunguntur, praemissa comment. de casuum, imprimis Genitivi et Dativi natura et potestate, Schulschriften des Grossherzog FriedrichFranz Gymnasiums zu Parchim (Heft 5), Parchim.

Wisseler, [?], 1837, De dativo cum verbis passivis coniucnto Lat. Scriptoribus cum Graecis communi, Wesel.

Pabst, C.Th., 1840, De locutione 'quid sibi vult', Arnstadt, Progr.

Müller, L.M., 1846, De attractionis apud Lat. Eo genere, quo post verbum licet et similia dativum vel accusativum praedicati cum verbo finito esse et aliis eiusdem potestatis iungunt, Goglau.

Fischer, V.D., 1853, Die rectionslehre bei Caesar (Acc. et Dat.), Halle, Progr.

Lehmann, A., 1863, De verborum compositorum quae apud Sallustium, Caesarem, Livium, Tacitum leguntur cum dativo strcutura commentatio, Breslau, Diss.

Augustin, A., ca. 1869, De usu dativi atque praepositionum in structura verborum compositorum quae apud Ciceronem leguntur, Ratibor, Progr.

Lorenz, K., 1871-1874, Beobachtungen über den Dativ der Bestimmung, besonders den Dativ des Gerundius bei Livius (I-II), Progr. Meldorf.

Dittel, H., 1873, Der Dativ bei Vergil, Innsbruck, Progr. Gymn.

Schroeter, G., 1873, Der Dativ zur Bezeichnung der Richtung in der lateinischen Dichtersprache, Sagan, Progr.

Nieländer, F., 1874, Der factitivi Dativus in den ciceronianischen Schriften, Krotoschin, Progr.

Schlueter, C., 1874, De accusativi et dativi usu Terentiano, Münster, Diss.

Ignatius, W., 1877, De verborum cum praepositionibus compositorum apud Cornelium Nepotem, T. Livium, Curtium Rufum cum dativo structura, Halle, Diss.

Nieländer, F., 1877, Der factitivi Dat. bei röm. Dichtern und Prosaikern (I), Schneidemühl, Progr.

Dittel, H., 1878, De dativi apud Horatium usu, Landskron in Böhmen. 
Hahn. H., 1878, De verborum cum praepositionibus compositorum apud veteres Romanorum poetas scaenicos cum dativo structura, Halle, Diss.

Hauser, Ch., 1878, Der participiale Dativ des örtlichen und geistigen Standpunctes nach Ursprung und Gebrauch bei den lateinischen Schriftstellern, Bozen, Progr.

Knös, W., 1878, De dativi finalis qui dicitur usu Taciteo, Uppsala, Diss.

Peine, H., 1878, De Dativi apud priscos scriptores Latinos usu, Estrasburgo, Dissert.

Arnold, S.K., 1880, «The "Predicative Dative" in latin», Transact. of the Cambr. Philol. Soc., pp. 261-265.

Keller, H., 1880, De verborum cum praepositionibus apud Lucretium usu, Halle, Diss.

Ulrich, Fr., 1880, De verborum compositorum quae extant apud Plautum structura commentatio, Halle, Progr.

Schneemann, C., 1881, De verborum cum praepositionibus compositorum apud Catullum, Tibullum, Propertium structura, Halle, Diss..

Tillmann, H., 1881, «De dativo verbis passivis linguae Latinae Subiecto, qui vocatur Graecus», Acta sem. Philol. Latinae Erlangensis 2, pp. 71-139 [1880, Erlangen, Diss.].

Wölfflin, Ed., 1881, «De dativo, qui dicitur iudicantis», Acta Semin. Phil. Erlangensis 2, p. 140.

Oesterberg, P.I., 1883, De structura verborum cum praepositionibus compositorum, quae exstant apud C. Valerium Flaccum, P. Papinium Statium, M. Valerium Martialem, Uppsala, Diss.

Iber, H., 1888, De dativi usu Tibulliano, Diss. Marburg.

Sitzler, J., 1889, Ueber den Kasusgebrauch bei Varro (I: Genetiv und Dativ), Tauberbischofsheim, Progr.

Riemann, O., 1890, «Remarques sur diverses questions de syntaxe latine (suite): IV.- Est aliquid argumento, damno, etc.», RPh 14, pp. 63-70.

Naumann, F., 1892, De verborum cum praepositionibus usu Amiani Marcellini, Erlangen, Diss.

Schenk, R., 1892, De dativi possessivi usu iceroniano (I), Jena, Fromannsche Buchdr. (Berggedorf, Hansa-schule Progr.).

Landgraf, G., 1893, «Der Dativus commodi und der Dativus finalis mit ihren Abarten», ALL VIII, pp. 39-76.

Nielaender, Fr., 1893, Der faktitive Dativ b. d. lat. Prosaikern und Dichtern (II), Schneidemühl, Progr.

Nielaender, Fr., 1894, Der faktitive Dativ b. d. lat. Prosaikern und Dichtern (III), Schneidemühl, Progr. 
Czyckkiewicz, A., 1896, De dativi usu Taciteo. Progr. Brody.

Geyer, P., 1896, «Männliche Verbalsubstantiva mit dem Casus des Verbums», $A L L$ IX, p.577.

Miles, E.H., 1897, «The 'Dative' of the possessor», ClR XI, pp. 142-143.

Schramm, E., 1897, De Ciceronis libris de legibus recensendis: inest birtii de 'quo' dativo appendix, Marpurgi Chattorum [1896, Marburg, Diss.].

Gustafsson, F.,1899, Forhandlinger paa det femtenordiske filologmode, Kristiania.

Lastavec, F., 1899, De verborum cum praepositione compositorum apud Vergilium cum Dativo structura, Viena, Diss.

Schunk, J., 1900, Quantum intersit inter Dativi poss. usum Ciceronis et Plauti, Zweibrücken, A. Kranzbühler (Erlangen, Diss.).

Buecheler, F., 1903, «Amatissimo suis», Mélanges Boissier, Paris, pp. 86-90.

Gustafsson, F., 1904, De dativo Latino, Helsinki, Ed. Weillin \& Gööds.

Dewing, H.R., [1905], The latin indirect object governed by verbs of favoring, helping, etc., Diss. Berkeley High School (reseña en TAPhA 36, 1905, pp. lxiii-lxiv).

Nutting, H.C., 1906-1907, «The Dative with certain Intransitive Verbs», CJ 2, pp. 250-267.

Lease, E.B., 1907, «The dative with prepositional compounds (I)», AJPh 28, pp. 2752.

Martha, J., 1907, «Quo datif», RPh XXXI, p. 27.

Fay, E.W., 1910, «On the construction of facere (sacrificare) quasi donare», $C P h$ 5, p. 368.

Müller, C.F.W., 1910, «Die Syntax des Dativs im Lateinischen», Glotta 2, pp. 169181.

Fay, E.W., 1911, «The Latin Dative: Nomenclature and Classification», Classical Quaterly 5, pp. 185-195.

Lenchantin de Gubernatis, M., 1911, «Pendêre col dat. di contatto», BFC 17, p. 281.

Solmsen, F., 1911, «Zur Geschichte des Dativs in den indogermanischen Sprachen», ZVS 44, pp. 161-223.

Steele, R.B., 1911, Case usage in Livy (II: The dative), Leipzig.

Allen, B.M., 1912, CW 5, pp. 170-173.

Havers, W., 1912, «Daivus sympatheticus», BSL 18, p. 34.

Koch, H., 1912, «Der epexegelischer Genitiv bei Cyprian», ZNTW 13, pp. 165-170.

Landgraf, G., 1912, «Dimissui esse bei Cicero pro Rosc. Am. § 11», Berliner philologische Wochenzeitschrift 32, pp. 1299-1301.

Lease, E. B., 1912 ${ }^{\mathrm{a}}$, «Prepositional compounds with the dative in High-School Latin 
at the first year in college», $C J 8$, pp. 7-16.

Lease, E. B., $1912^{\text {b }}$, «The dative with prepositional compounds (II)», AJPh 33, pp. 285-300.

Havers, W., 1913, «Zum Gebrauch des Dativs in den italischen dialekten», Glotta 5 , pp. $1-8$.

Geisau, J. von, 1914, «Zum Dativus comparationis im Lateinischen», BPhW 34, pp. 222-223.

Lenchantin de Gubernatis, M., 1914, «Pendêre col dat. di contatto», BFC 20/9, p. 206; y 20/12, pp. 280-284.

Rasi, R., 1914, «Pendere col dativo di contatto?», BFC 20/11, pp. 254-255.

Vendryès, J., 1914, reseña de A. Greeen, The dative of agency, a chapter of indoeuropean case-syntax, Nueva York, 1913, en BSL 19 (1914-1916), pp. 43-46.

Schmalz, J.H., 1916, «Zum doppeltten Dativ im Lateinischen», BphW, pp. 11231127.

Nutting, H.C., 1920-1921, «The dative with certain compound verbs», CJ 16, pp. 368-369.

Baxter, J.H., 1924, «Some predicative datives in late latin», ALMA 1, pp. 85-88.

Novotný F., 1924, «Latinský dativus effectivus», Listý filologieké 51, pp. 77-93 (sintetizado por A. Klotz en $P h W$ 45, 1925, p. 879).

Tosatto, C., 1924, 1925, De dativi usu apud Florum et Justinum, Padua.

Souter, A., 1925, «The predicative dative specially in later latin», ALMA 2, pp. 191194.

Stout, E., 1925, «I. The constructions invideo aliquid alicui and invideo alicui aliqua re. II. Invideo aliis bonum quo or invideo aliis bono quo in Plin., Ep. I 10.12», CPh 20, pp. 145-154.

Biedl, A., 1928, «Zur Dativkonstruktion bei Sallust», PhW 48, pp. 1148-1149.

Marouzeau, J., 1928, «Cronique», REL 6, pp. 259-266.

Brouwer, F.C., 1931, «De Latijnsche dativus en zijn functie», en Handelingen Nederl. Philologencongress, 14, pp. 32-34.

Johnson, I.L., [1932], A study of the dat. of purpose in Caesar, State Teachers College, Carbondale III (reseñado en TAPhA 53, 1932, p. lvii , núm. 32).

Ulseth, U.F., 1933, «Die Konstruktionen bei succedere als militärische termina technica» (sic!), Overbilb. W. Munthe Oslo, pp. 478-480.

Baxter, J.H., 1934, «More predicative datives», ALMA 9, pp. 98-100.

Groselj, M., 1934, Iz sinfakse latinskega genetiva in dativa, Maribor, Ljudska Tisk (Laibach, Diss.).

Laborderie, R., 1934, «Pour une histoire du datif latin», REL 12, pp. 278-280. 
Richardson, L.J.D., 1936, «The dative of agent in Horace's Odes», CR 50, pp. 118120.

Werner, J., 1937, «Predicative datives in Mediaeval Latin», ALMA 11, pp. 35-39.

Elg, A. G., 1947, «De usu dativi comparationis apud Faustum Reiensem», Eranos 45, pp.78-80.

Löfstedt, B., 1963, «Zum lateinischen possessiven Dativ», Zeitschrift für vergleichende Sprachforschung 78, pp. 64-83.

Iliescu, M.-Macarie, L., 1964, «Aspects de l'évolution syntaxique du genitif et du datif en latin tardif», Revue roumane de linguistique 9, pp. 437-444.

Herman, J., 1965, «Le datif possessif dans la latinité balkanique», en Omagiu lui A. Rossetti, Bucarest, pp. 375-378.

Lunelli, A., 1969, «Laboranti similis (Verg., Georg. III 193)», Maia 21/4, pp. 341342.

Traina, A., 1969, «Laboranti similis. Storia di un omerismo virgiliano», Maia 21/1, pp.71-78.

Colucci, Loris, 1974, «Facilis descensus Averno», RIL 104, pp. 180-195.

Schramboeck, H., 1975, Der sympathetische Dativ in der latenisichen Dichtersprache der klasischen und nachklassischen Zeit, Viena, Diss.

Marečková-Štolková, Elena, 1975, «Ein Beitrag zur Charakteristik der Funktionsauslastung der lateinischen Kasus (der Dativ)», en J. Ceska (cur.), Classica atque meiaevalia Jaroslao Ludvíkovský octogenario oblata, Brno, pp. 91-99.

Pepicello, W. J., 1977, «The Syntax of Dative- and Accusative-Infinitive Constructions», Papers from the $13^{\text {th }}$ Regional Meeting Chicago Lingustic Society, pp. 472-479.

Happ, H., 1978, «Impedimento est bei Caesar», Gymnasium 85, p. 437.

Murru, Furio, 1978, «Alcune questioni filológico-linguistiche a proposito dell' octavus casus», Glotta 56, pp. 144-155.

Romeo Pallás, J. Ma ., 1978, «El uso del dativo en los tratados De lapsis y De Catholicae Ecclesiae unitate de San Cipriano», Anuario de Filología (Barcelona) 4, pp. 135-144.

Murru, F., $1979^{\text {a }}$, «Due ulteriori definizioni dell'octavus casus nei grammatici latini», Glotta 57, pp. 155-157.

Pugliarello, M., 1979, «Un grecismo sintattico: idem + dativo», Paideia 34, pp. 113119.

Serbat, G., 1980, «Le datif chez Pétrone», VL 112, pp. 2-10.

Colucci, L., 1981, Prospettive per una reinterpretazione del dativo in Virgilio, Roma.

Dér, T., 1981, A kett» os kötes» u dativus Horatiusnál [Der Gebrauch des Dativus 
mit Doppelanknüpfung bei Horaz], Szeged.

Murru, F., 1981, «Per una reinterpretazione del dativo in Virgilio», Misc. ling. Vichiana 10, pp. 223-227 (a propósito de L. Colucci 1981, Prospettive etc.).

Traglia, A., 1981, «Un dativo in -ai negli Aratea dei Cicerone?», RFIC 109, pp. 286-297.

Colucci, L., 1982, Structure sintattiche e stilistiche in Virgilio: 'it clamor caelo', Chieti.

Maurel, J.-P., 1982, «Datifs libres et datifs liés enn latin», Cahiers de grammaire (Toulouse) 4, pp. 59-92.

Bolkestein, A.M., 1983, «Genitive and dative possessors in Latin», en S.C. Dik (ed.), Advances in Functional Grammar, Dodrecht/Cinnaminson, pp. 55-91.

Bonelli, G., 1983, «Dativo direzionale e significato delle funzioni sintattiche», Latomus 42, pp. 863-868.

Lambert, P.-Y., 1983, «Fraudativus: une dénomination ancienne du dativus incommodi dans le monde celtique», $R P h$ 58, pp. 39-45.

Théoret, M., 1984, «Statistique et langue latine: la consurrence datif/accusatif ou ablatif prépositionnel», Révue Québécoise deLinguistique Théorique et Appliquée 3, pp. 123-150.

Lavency, M., 1985, «Datif d'attribution et datif d'intérêt en latin classique», CILL 11, pp. 41-51.

Marečková-Štolková, E., 1985, «Valenzbeziehunggen von lateinischen Verben mit der Dativ-Rektion», Sbornik Praci Filos. Fac Brn. E 30, pp. 149-160 (en checo, con un resulmen al final del mismo en alemán, pp. 159-160).

García González, F.J., 1986, «Consideraciones en torno al dativo de juicio», $E F G$, pp. 219-226.

Martín Rodríguez, A.Mª., 1986, «Algunas observaciones sobre el dativo en Plauto», Estudios Humanísticos. Filología 8, pp. 87-96.

García Hernández, B., 1986-87, «Gramática de casos y disociación intrasubjetiva: dativo profundo y dativo funcional», CFC 20 (Homenaje al Prof. L. Rubio), pp. 231-248.

Christol, A., 1989, «Pour une typologie de l'olbigation, II. 'Dativus auctoris' ou personne concernée?», CILL 15 (M. Lavency-D. Longrée (eds.), Actes du Ve Colloque de Lingusitique Latin), Lovaina, pp. 67-75.

Clúa, J. A., 1989, «El llatí epigràfic de la Safor valenciana», Faventia 11, pp. 127136.

Schenkeveld, D.M., 1989, «Antiphon, Or. V,8: a case of a dative of purpose?», Mnemosyne 42, pp. 474-476.

Serbat, G., $1989^{\text {a }}$, «Le datif dans les Boucoliques de Virgile», Minerva 3, pp. 213- 
229.

Elerick, Ch., 1990, «Latin as an SDVO Language: the evidence fron Cicero», en G. Calboli (ed.), Papers on Grammar III, pp. 1-17, Bolonia.

Serbat, G., 1990, «Le datif dans les Catilinaires de Cicéron», Bulletin of the Institute of Language Teaching (Waseda University, Tokyo) 40, pp. 23-43.

García Hernández, B., 1992 a , «El dativo con sum, ¿un dativo específico?, en Humanitas. In honorem A. Fontán, Madrid, pp. 63-69.

García Hernández, B., $1992^{\text {b }}$, «El dativo con sum y la vulgarización de la noción de posesión», RSEL 22, pp. 325-337.

Serbat, G., 1992, «Julian de Tolède et l'octavus casus: Un mirage significatif», Humanitas, in honorem A. Fontan, Madrid, pp. 71-77.

Suárez Martínez, P.M. (1992), «Dono dare: el reflejo de un espejismo sintáctico en latín», Emerita 60, pp. 31-40.

Folgar, C., 1993, Diacronía de los objetos directo e indrecto (del latín al castellano medieval), Santiago de Compostela.

García Hernández, B., 1993, «Die komplementäre Beziehung zwischen mihi est und habeo. Ihre historische Entwicklung», IF IIC, pp. 186-199.

Cabrillana, C., 1994, «Factores catalizadores en la ordenación de constituyentes: el caso particular de D y O», Actas del VIII Congreso Español de Estudios Clásicos, Madrid, t. I, pp. 443-450.

Echarte, $M^{\text {a }}$. J., 1994, «Sobre el valor del dativo en latín. El llamado dativo de dirección y el dativo con verbos prefijados», Minerva 8, pp. 211-241.

García Hernández, B., 1994, «From lexemics to syntax: the double accusative with doceo and the dative with sum», en J. Herman (ed.), Linguistic Studies in Latin, Amsterdam, pp.379-392.

Hoecke, W. van, 1994, Le datif latin, Lovaina.

García Hernández, B., $1995^{\text {a }}$, El dativo latino. Funciones e interferencias sintácticas y semánticas», en $\mathrm{M}^{\mathrm{a}}$ E. Torrego - P. J. Quetglas - E. Espinilla (eds.), Sintaxis del dativo latino, Barcelona, pp. 35-49.

García Hernández, B., $1995^{\text {b }}$, «El dativo llamado posesivo: una confunsión terminológica y conceptual», en De usu. Ëtudes de syntaxe latine offertes en hommage à M. Lavency, Lovaina, pp. 155-162.

Baños Baños, J.M., 1995, «El "doble dativo" en latín», en $\mathrm{M}^{\mathrm{a}}$ E. Torrego - P. J. Quetglas - E. Espinilla (eds.), Sintaxis del dativo latino, Barcelona, pp. 11-34.

Gutiérrez Galindo, M.A., 1995, «Sintaxis, semántica y pragmática del dativo de dirección en latín», en $\mathrm{M}^{\mathrm{a}}$ E. Torrego-P.J. Quetglas-E. Espinilla (eds.), Sintaxis del dativo latino, Barcelona, pp. 51-60.

Iso Echegoyen, J. J., 1995, «La construcción sum + dativo y habere + acusativo co- 
mo expresión de la posesión», en $\mathrm{M}^{\mathrm{a}}$ E. Torrego - P. J. Quetglas - E. Espinilla (eds.), Sintaxis del dativo latino, Barcelona, pp. 61-74.

Martín Rodríguez, A. Mª (1995), «Aliquem aliqua re donare /aliquid alicui donare. Cuestiones de sintaxis, semántica y pragmática», en $\mathrm{M}^{\mathrm{a}}$ E. Torrego-P.J. Quetglas-E. Espinilla (eds.), Sintaxis del dativo latino, Barcelona, pp. 75-94.

Moralejo Álvarez, J. L., 1995, «El dativo regido como complemento único», en $\mathrm{M}^{\mathrm{a}}$ E. Torrego - P. J. Quetglas - E. Espinilla (eds.), Sintaxis del dativo latino, Barcelona, pp. 95-104.

Baños Baños, J. M., 1996, «Litteras Neroni / ad Neronem mittere: ¿alternancia dativo / ad + acusativo?», en A. Agud - J. A. Fernández Delgado - A. Ramos (eds.), Las lenguas de corpus y sus problemas lingüísticos, Madrid-Salamanca, pp. 217-235.

Echarte, Ma J., 1996, «Acusativo y dativo: dinámica sincrónica del latín al castellano», RSEL 26, pp. 83-107.

Hoecke, W. van, 1996, «The Latin dative», en W. van Belle-W. van Langnedonck (eds.), The dative, Amsterdam-Philadelphia, t. I, pp. 3-37.

Joffre, M. D., 1996, «L'évolution sémantique de habere; habere concurrent du datif», en Les structures de l'oralité en latin, París, pp. 193-198.

Martín Rodríguez, A. M M $^{\mathrm{a}} 1996^{\mathrm{c}}$, «Verbes à double régime et contraintes de genre littéraire. Apercu diachronique sur donare», en A. Bammesberger-F. Heberlein (eds.), Akten des VIII. intenationalen Kolloquiums zur lateinischen Linguistik, Heidelberg, pp. 213-221.

Mellado, J., 1996, «Complementos del verbo y complementos del predicado: El dativo "adnominal"», en A. M ${ }^{\mathrm{a}}$ Aldama (ed.), De Roma al siglo XX, Madrid, t. I, pp. 93-102.

Serbat, G., $1996^{\text {b }}$, «Essai de définition du datif latin», en A. Bammesberger-F. Heberlein (eds.), Akten des VIII. intenationalen Kolloquiums zur lateinischen Linguistik, Heidelberg, pp. 154-164.

Langendonck, W. van, 1996-1998, «The dative in Latin and the indirect object in Dutch», en W. van Langendock-W. van Belle (eds.), The dative (I-II), Amsterdam, t. I, pp. I211-259.

Baños Baños, J. M., 1998, «Sintaxis y semántica del dativo 'objeto indirecto': su concurrencia con $a d$ + acus. en latín clásico», en $\mathrm{M}^{\mathrm{a}} \mathrm{E}$. Torrego (ed.), Nombres y funciones: Estudios de sintaxis griega y latina, Madrid, pp. 11-41.

Bortolussi, Bernard, 1998, «Esse + datif et esse + génetif en latin», en A. Rouveret (ed.), 'Être' et 'avoir': Syntaxe, sémantique, Typologie, Saint-Denis, pp. 67-94.

Baños Baños, J. M., 2000, «Vulgarismos sintácticos en Plauto (II): quae ad patrem vis nuntiari (Cap. 360)», en B. García Hernández (ed.), Latín vulgar y tardío. Homenaje a V. Vaänaänen (1905-1997), Madrid, pp. 1-16. 
García Hernández, B., 2002, «Los nombres del dativo y la función de destinatario», en A.M. Bolkestein et alii, Theory and description in Latin Linguistics (Selected Papers from the Xith International Colloquium on Latin Linguistics), Amsterdam, pp. 139-152.

Gutiérrez Galindo, M.A. (en prensa), «Los estudios sintáctios sobre el dativo en los siglos XIX y XX».

\section{BIBLIOGRAFÍA COMPLEMENTARIA}

Allen, F. D., 1897, «Brenous on Hellenisms in latin» (reseña de J. Brenous, Études sur les Héllenismes dans la Syntaxe Latine, París, 1895), CR 11, pp. 160-162.

Álvarez Benito, G., 1992, «Revisión de las Gramáticas de casos», Philologia Hispalensis 7, pp. 257-273.

Arutjunova, N. D., 1975, «Problems of Syntax and Semantics in the works of Charles Fillmore», Linguistics 150, pp. 5-14.

Baldi, Ph., 1973, Deponent and middle in Latin, Ann Arbor, Michigan.

Barss, J. E., 1927, «The drammatic element in Latin Grammar», Classical Weekly XX, pp. 123-128.

Bauer, B., 1996, «Residues of non-Nominative Syntax in Latin: The Mihi est construction», Historische Sprachforschung CIX, pp. 241-256.

Bassols de Climent, M., 1945-1948, Sintaxis histórica de la lengua latina (I-II/1), Barcelona, CSIC.

Bassols de Climent, M., 1956, Sintaxis latina (I-II), Madrid, CSIC.

Bastardas, J., 1953, Particularidades sintácticas del latín medieval (cartularios españoles de los siglos VIII al XI), Barcelona, CSIC.

Blake, B., 1994, Case, Cambridge.

Benveniste, E., 1963, «Être et avoir dans leurs fonctions linguistiques», BSL LV, pp. 113-134.

Bennett, Ch. E., 1910-1914, Syntax of early latin (I-II), Boston/Leipzig.

Binkert, P. J., 1970= 1977, Case and prepositional constructions in a Tranformational Grammar of Classical Latin, Universidad de Michigan, Tesis.

Birt, Th., 1908, «Einiges, was uns die Handschriften lehren», Archiv für lat. Lex. XV, pp. 74-87.

Blansitt, E.L., Jr., 1973, «Bitransitive Clauses», Working Papers in Language Universals XIII, pp. 1-26.

Bolkestein, A.M., 1980, Problems in the description of modal verbs. An investigation of Latin, Assen.

Bonnet, M., 1890 = 1968, Le latin de Grégoire de Tours, París = Hildesheim.

Brenous, J., 1895 = 1965, Étude sur les Hellénismes dans la syntaxe latine, París = Roma.

Burger, A., 1943, «Pour une théorie du Roman commun», en Mémorial des Études Latines offerts à J. Marouzeau, París.

Buttmann, Ph., 1829, Griechische Grammatik, Berlín.

Cabrillana, C., 1993, «Posiciones relativas en la ordenación de constituyentes (I). Estudio de la posición de sujeto, objeto y verbo en latín», Habis XXIV, pp. 249-266.

Cabrillana, C., 1994, «Posiciones relativas en la ordenación de constituyentes (II). Estudio de la posición de sujeto, predicado nominal y verbo en latín clásico», Habis XXV, pp. 251-460.

Cabrillana, C., $1997^{\text {a }}$, «Expresión casual de complementos de uenio y eo», Habis XXVIII, pp. 325-336.

Cabrillana, C., $1997^{\text {b }}$, «Complementos direccionales en el marco predicativo de uenio», Minerva XI, pp. 117-137.

Calboli, G., 1972, La linguistica moderna e il latino. I casi, Bolonia.

Calboli, G., 1983, «Problemi di grammatica latina», en H. Temporini-W. Haase (eds.), Aufstieg und Nie- 
dergang der Römischen Welt II 29/1, Berlín/Nueva York.

Carnoy, A. $\left(1906^{2}\right)$, Le latin d'espagne d'après les inscriptions. Étude linguistique, Bruselas.

Carvalho, P. de, 1978, «Syntaxe et sémantique. Verbe et phrase en latin», Revue des études anciennes 80, pp. 239-247.

Carvalho, P. de, $1980^{\text {a }}$, «Cas et Personne. Propositions pour une théorie morpho-sémantique des cas latins», Revue des Études Anciennes (Ann. De l'Univ. de Bordeux III), LXXXII, pp. 243-274.

Carvalho, P. de, $1980^{\text {b}}$, «Cas et prépositions en latin (à propos de de Virg.. En. 1,1-3)», Orphea uoce (Univ. de Bordeux III) I, pp. 23-106.

Carvalho, P. de, $1980^{\text {c }}$, «Réflexions sur le cas: vers une théorie des cas latins», L'Information Grammaticale VII, pp. 3-11.

Carvalho, P. de, 1983, «Le système des cas latins. Aperçu d'une théorie morpho-sématique», en H. Pinkster (ed.), Theoretical and descriptive studies in Latin Linguistics. Proceedings of the $1^{\text {st }}$ International Colloquium on Latin Linguistics, Amsterdam, pp. 59-71.

Carvalho, P. de, $1985^{\text {a }}$, Nom et declinación. Recherches morpho-syntaxiques sur le mode de représentation du nom en latin(I-II), Burdeos.

Carvalho, P. de, $1985^{\text {b }}$, «Nominatif et subjet. Pour une "grammaire des cas" postfillmorienne», en Ch. Touratier (ed.), Syntaxe et latin. Actes du IIme Congrès International de Linguistique Latine, Aixen-Provence.

Carvalho, P. de, $1996^{\text {a }}$, «Cas et prépositions en lingusitque latine et en ligusitique théorique», en H. Rosén (ed.), Aspects of Latin. Papers from the 7th International Colloquium on Latin Linguistics, Innsbruck, pp. 241-259.

Carvalho, P. de, $1986^{\text {b }}$, “Syntaxe” ... en latin?», BSL LXXXI, pp. 275-301.

Compernass, J., 1914, «Vulgärlatein», IF XXXIV, pp. 220-224.

Cousin, J., 1951, Bibliographie de la langue latine (1880-1948), París.

Cremaschi, G., 1959, Guida allo studio del latino medievale, Padua.

Devoto, G., 1940, Storia della lingua di Roma, Bolonia.

Crespo, E., 1997, «Sintaxis de los elementos de relación en griego clásico», en Actas del IX Congreso de la SEEC, Madrid, t. I, pp. 3-42.

Delbecque, N. - Lamiroy, B., 1996-1998, «Towards a typology of the Spanish Dative», en W. van Langendock-W. van Belle (eds.), The dative (I-II), Amsterdam, t. I, pp. 73-117.

Díaz y Díaz, M. C., 1952, «Notes lexicographiques espagnoles», ALMA XXII, pp. 77-85.

Díaz y Díaz, M.C., 1959, «El latín de la Península Ibérica. Rasgos lingüísticos», en Enciclopedia Lingüística Hispánica (I), Madrid, CSIC, pp. 153-197.

Díaz y díaz, M.C. (1960), «Un document privé de l'Espagne wisigothique sur ardoise», Studi medievali I, pp. 52-71.

Díaz y Díaz, M.C., 1965, «El latín de la liturgia hispánica. Notas introductorias», en Estudios sobre liturgia mozárabe, Toledo, pp. 55-87.

Díaz y Díaz, M.C., 1966, «Los documentos hspano-visigóticos sobre pizarra», Studi medievali VII, pp. 75-107.

Dietrich, F., 1851, «Über den nordischen Dativ», Zeitschrift für deutsches Alterthum VIII, pp. 23-88.

Dik, S.C., 1978 = 1981), Gramática functional, Madrid.

Dik, S.C., 1997, The theory of Functional Grammar (I-II), Berlín/Nueva York, (edición preparada por K. Hengeveld).

Dowty, D.R., 1978, «Governed transformations as Lexical Rules in a Montague Grammar», Linguistic Inquiry IX, pp. 393-426.

Draeger, A., 1878, Historische Syntax der lateinischen Sprache (I²-II), Leipzig. 
Dubský, O., 1929, «Sur quelques constructions verbales dans les langues romanes de l'ancienne époque», Revue de linguistique romane $\mathrm{V}$, pp. 299-341.

Dumitrescu, D., 1990, «El dativo posesivo en español y en rumano», RSEL 20, 403-429.

Ebinger, J., 1865, De casuum obliquorum in lingua Latina vi et usu, Progr.

Echarte, Mª J., 1985, «Meditaciones sobre dos métodos para el análisis de la lengua latina: generativismo y funcionalismo», Estudios Clásicos XVIII, pp. 156-169.

Echarte, $M^{\mathrm{a}}$. J., 1989, «Sobre la estructura de la oración latina II: Valor de los casos en el sistema», en Actas del VII Congreso español de Estudios Clásicos, Madrid, t. I, pp. 439-444.

Echarte, $\mathbf{M}^{\mathrm{a}} . \mathrm{J} ., 1^{2}{ }^{\mathrm{a}}$ ), «Casos y preposiciones en latín», en Miscel-lània homenatge Enrique García Diez, Valencia, pp. 313-320.

Echarte, M $^{\mathrm{a}}$ J., $1991^{\text {b }}$, «Los casos en la estructura del latín», Minerva VI, pp. 167-188.

Echarte, Ma J., 1998, «Preposiciones y casos en latín: propuesta de un sistema conjunto», en B. García Hernández (ed.), Estudios de lingüística latina, Madrid, pp. 309-323.

Elerick, Ch., 1989, «Gapping, Preemptive Markedness and Word Order in Latin», en G. Calboli, Latin Lingusitics and Linguistic Theory. Proceedings of the third Colloquium on Latin Lingusitics, Amsterdam, pp. 559-571.

Elerick, Ch., 1990, «Latin as an SDVO Language: the evidence fron Cicero», en G. Calboli (ed.), Papers on Grammar III, pp. 1-17, Bolonia.

Elvira González, J., 2000, «Observaciones sobre una declinación bicasual en la última etapa del latín de Hispania», en B. García-Hernández (ed.), Latín vulgar y tardío. Homenaje a V. Vaänänen (19051997), Madrid, pp. 31-44.

Ernout, A., 1944, Reseña de E. Löfstedt, Syntactica, Lund, $1942^{2}$, RPh XVIII , pp. 175-197.

Ernout, A. - Thomas, F., $1959^{2}$, Syntaxe Latine, París.

Fernández Lagunilla, M. - Anula Rebollo, A. (y colaboradores), 1995, Sintaxis y cognición. Introducción al conocimiento, el procesamiento y los déficits sintácticos, Madrid.

Fillmore, Ch.J., 1968, «The case for case», en E. Bach-R.T. Harms (eds.), Universals in Linguistic Theory, Nueva York, pp. 1-88.

Fillmore, Ch.J., 1971 = 1976, «Algunos problemas de la Gramática de casos», en V. Sánchez de Zabala (comp..), Semántica y sintaxis en la lingüística transformatoria [II], Madrid, pp. 171-200.

Fillmore, Ch. J., 1977, «The case for case reopened», en P. Cole-J. Sadock (eds.), Syntax and Semantics 8: Grammatical relations, Nueva York, pp. 59-81.

Fletcher, P., 1971, «Case grammar: Its viability as an alternative grammatical model», Lingua 28, pp. 237-250.

Fugier, H., 1998, «Les cas latins fonctionnent-ils en contre-emploi?», en B. García Hernández (ed.), Estudios de lingüística latina, Madrid, pp. 343-362.

García de la Fuente, O., 1994, Latín bíblico y latín cristiano, Madrid.

García Hernández, B., 1986, «Gramática de casos y lexemática», RSEL XVI, pp. 397-417.

García Hernández, B., 1998, «La expresión de la noción verbal de posesión del latín al romance», en L. Callebat (ed.), Actes du 4 e colloque international sur le latin vulgaire et tardif (2-5 september 1994), Hildesheim/Zúrich/Nueva York, pp. 323-336.

García Sanchidrián, Ma.L., 1998, «Del sistema casual a las preposiciones: Una muestra en Braulio de Zaragoza», en M. Pérez González (coord..), Actas II Congreso Hispánico de Latín Medieval (I), León, pp. 483-491.

Geisau, J. von, 1916, «Syntaktische Gräzismen bei Apulejus», IF XXXVI, pp. 70-98 y 242-287.

Giese, W., 1952, «Balkansyntax oder Thrakischer Substrat», Studia Neophilologica XXIV, pp. 40-54.

Gil, J., 1971, «Apuntes sobre la morfología de Álbaro de Córdoba», Habis II, pp. 199-206. 
Givón, T., 1984-1990, Syntax. A functional-Typological Intoruction, Amsterdam/Philadelphia.

González Muñoz, F., 1996, Latinidad mozárabe. Estudios sobre el latín de Álbaro de Córdoba, Córdoba - Coruña.

Grandgent, C.H., 1907 = 1928, Introducción al latín vulgar, Madrid, CSIC.

Green. A., 1913, The Dative of Agency: a chapter of Indo-European Case-syntax, Nueva York.

Grevander, S., 1926, Untersuchungen zur Sprache der 'Mulomedicina Chironis', Diss. Lund-Leipzig.

Groot, A. W. de, 1939, «Les oppositions dans les systèmes de la syntaxe et des cas», en Mélanges de linguistique offerts à Ch. Bally, Ginebra, pp. 107-127

Groot, A.W. de , 1956, «Classification of cases and uses of cases», en For Roman Jacobson, La Haya, pp. 187-194.

Guest, E., 1842-1844, «On the Use of the Dative in English syntax», Proceedings of the Philological Society $1,251-264$.

Gutiérrez Ordóñez, S., 1999, «Los dativos», en I. Bosque-V. Demonte (eds.), Gramática descriptiva de la lengua española (I-II), Madrid, t. I, pp. 1855-1930.

Happ, H., 1976, Grundfragen einer Dependenz-Grammatik des Lateinischen, Gotinga.

Harris, M., 1975, «Some problems for a case grammar of Latin and Early Romance», JL XI, pp. $183-$ 194.

Hau, P., 1884, De casuum usu Ovidiano, Münster, Diss.

Haudry, J., 1968, «Les emplois doubles du datif et la fonction de datif indo-européen», BSL LXIII, pp. 141-159.

Haverling, G., 1988, Studies on Symmachus' language and style, Goteborg.

Havers, W., 1911, Untersuchungen zur Kasussyntax der indogermanischen Sprachen, Estrasburgo.

Herrera Roldán, P.P., 1995, Cultura y lengua latinas entre los mozárabes cordobeses del siglo IX, Córdoba.

Herslund, M., 1988, Le datif en français, Lovaina-París.

Hidén, C.I., 1986, De casuum syntaxi Lucretiana, Helsingfors, 1896.

Hildebrand, G. F., 1854, Über enige Abweichungen im Sprachgebrauche des Cicero, Cäsar und Livius, Dortmund, Progr.

Hildebrand, G. F., 1865, Beiträge zum Sprachgebrauch des Livius und zur Festellung des Textes seiner Historien, Dortmund, Progr.

Hjelmslev, L., 1935-1937 = 1978, La teoría de los casos, Madrid.

Hoerle, A., 1887, De casuum usu Propertiano, Halle, Diss.

Hofmann, J. B., 1951 = 1958, El latín familiar, Madrid, CSIC.

Hofman, J. B.- Szantyr A., 1972, Lateinische Syntax und Stilistik [I-II], Múnich.

Hoyo, J. del, 2001, «Nuevo estudio del carmen epigraphicum de Pomponio», SPhV V, pp. 27-42.

Howard, H., 1899, Case usage in Petronius' satires, Bloomington, Diss.

Hübner, E., 1876, Grundriss zu Vorlesungen über die Lateinische Grammatik, Berlín.

Hübschmann, H., 1875, Zur Casuslehre, Múnich.

Hüser, B., 1863, De casuum usu syntactico, Münster, Diss.

Ignatius, W., 1877, De verborum cum praepositionibus compositorum apud Corn. Nep., T. Livium, Curtium Rufum, Berlín.

Iso Echegoyen, J. J., 1975, «El término ablatiuus en el Ars Grammatica», CFC IX, pp. 33-52.

Jakobson, R., 1936, 1958 = 1975, «Contribución a la teoría general de los casos», en Ensayos de lingüística general, Barcelona, pp. 235-306.

Joffre, M.D., 1996, «L'évolution sémantique de habere; habere concurrent du datif», en Les structures 
de l'oralité en latin, París, pp. 193-198.

Kirtland, J. C., 1912, «The direct method of teaching the classics: The availability of the method for american schools», CJ VIII, pp. 355-363.

Konjetzny, G. (1908), «De idiotismis syntacticis in titulis Latinis urbanis (C.I.L. vol. VI) conspicuis», ALL XV, pp. 297-351.

Kroll, W., 1925 = 1935, La sintaxis científica en la enseñanza del latín, Madrid, (se dice que se toma como referencia la tercera edición alemana de la obra, pero no se da el año de la misma).

Kühner, R.-Stegmann, C., 1912-1914 ${ }^{2}=1962$, 4ed. corr., Ausfürliche Grammatik der Lateinischen Sprache (I-II/I-2), [Hannover] Darmstadt.

Kurylowicz, J., 1949, «Le problème du classement des cas», Boulletin de la Societé polonaise de linguisitique (B.P.T.J.) 9, pp. 20-43 (=Esquisses linguistiques, Wroclaw-Krakow (1960), pp. 131-150).

Kurylowicz, J., 1964, The inflectional categories of Indo-European, Heidelberg.

Lakoff, R.T., 1968, Abstract Syntax and Latin Complementation, Cambridge, Mass.

Lambertz, Th., 1982, Ausbaumodell zu Luzien Tesnières Élémentsde Syntaxe Structurale, Gerbrunn bei Würzburg.

Landgraf. G., 1903, Historische Grammatik desr lateinische Sprache (III/1: Syntax des einfachen Satzes), Leipzig, pp. 1-96.

Langendonck, W. van, 1996-1998, «The dative in Latin and the indirect object in Dutch», en W.van Langendock-W. van Belle (eds.), The dative (I-II), Amsterdam, t. I, pp. 211-259.

Lehmann, C., 1979, «Zur typologie des Lateinischen», Glotta LVII, pp. 237-253.

Lehmann, C., 1985, «Latin case relations in typological perspective», en C. Touratier (ed.), Syntaxe et latine. Actes du Iime Congrès international de linguistique latine, Aix-en-Provence, pp. 81-100.

Lenchantin de Gubernatis, M., $1914^{\text {a }}$, «Pendere col dat. di cotatto», Bolletino de Filologia Classica XX, pp. 206-207.

Lenchantin de Gubernatis, M., $1914^{\text {b }}$, «Pendere col dat. di cotatto», Bolletino de Filologia Classica XX, pp. 280-284.

Löfstedt, E., 1928-1933, Syntactica. Studien und Beiträge zur historischen Syntax des Lateins (I-II), Lund, (II: segunda edición, 1942).

Löfstedt, E., 1959 = 1980, Il latino tardo. Aspetti e problemi, Brescia.

Lohmann, A., 1915, De Graecismorum usu Vergiliano, Münster, Diss.

Luraghi, S., 1982, «Proposte per lo studio sistematico di preposizioni e morfemi casuali», SILTA XI, pp. 35-67.

Lejay, P., 1907, «Compte rendue», Revue critique LXIII, p. 206.

Maurel, J.P., 1989, inéd., Le syntagme nominal en latin. Les emplois du génitif chez Plaute et Térence, tomo I, Universidad de Estrasburgo, Tesis de Estado.

Mauro, T. de, 1965, «Il nome del Dativo e la teoria dei casi greci», Rend. della Academia Nazionale dei Lincei XX, pp. 1-16, 151-211 (reprod. en T. De Mauro 1971, Senso e significato. Studi di semántica teorica e storica, Bari, pp. 239-332).

Meillet, A., $1924^{\text {a }}$, «Le dévélopement du verbe avoir», en Antídôron. Festschrift J. Wackernagel zum Vollendung des 70 Lebensjahren, Gotinga, pp. 9-13.

Meillet, A., $1924^{\text {b }}$, «Latin interdico», BSL XXV, p. 104.

Meissner, I., 1891, Quaestiones ad usum casuum obliquorum Lucretianum pertinentes, Halle, Diss.

Mellema, P., 1974, «A Brief against Case Grammar», Foundations of Language XI, pp. 39-76.

Miăescu, H. (1978), La langue latine dans le sud-est de l'Europe. Bucarest-París.

Mohrmann, Ch., 1961²-1965, Études sur le latin des chrétiens (I-III), Roma.

Moralejo, J.L. 1986, «Sobre los casos latinos», RSEL XVI, pp. 293-323. 
Murru, F., 1979 a , «La "gramatica dei casi” e l'insegnamento del latino», en G. Proverbio 1979, pp. 282309.

Murru, F., $1979^{\mathrm{b}}$, «Entre philologie classique et linguistique apliquée: L'accustif de qualification et la 'grammaire des cas'», Revue Roumaine de Linguistique XXIV, pp. 591-604.

Newmeyer, F.J., $1980=1982$, El primer cuarto de siglo de la gramática generativo-tranformatoria (1955-1980), Madrid.

Oertel, Hans, 1941, Die Dativi finales abstrakter Nomina und andere Beispiele noinaler Satzfügung in der vedischen Prosa, Múnich.

Pak, T., 1974, «Absurdities in Fillmore's case grammar», SL XXVIII, pp. 19-50.

Palmer, L.R., $1954=1988^{2}$, Introducción al latín, Barcelona, Ariel.

Pepicello, W..J., 1977, «The Syntax of Dative- and Accusative-Infinitive Constructions», Papers from the $13^{\text {th }}$ Regional Meeting Chicago Lingustic Society, pp. 472-479).

Pérez González, M. (1985), El latín de la consillería castellana (1158-1214), Salamanca-León.

Petersen, W., 1918, «Syncretism in the Indo-European dative (I)», AJPh XXXIX, pp. 1-26; 117-144.

Petzl, G., 1981, «MNHMHÓ (MNEIAÓ) XARIN mit Dativ und Genetiv», Zeitschrift für Papyrologie und Epigraphik XLI, p.106.

Pinkster, H., 1972, «Het Latijnse naamvalssysteem», Lampas V, pp. 28-47.

Pinkster, H., 1980, «Naamvallen in een valentiegrammatica», Lampas XIII, pp. 111-129.

Pinkster, H., 1985, «Latin cases and valency grammar. Some problems», en Ch. Touratier (ed.), Syntaxe et latin. Actes du Iime Congrès International de Linguistique Latine, Marsella, 163-189.

Pinkster, H., 1990 = 1995, Sintaxis y semátnica del latín, Madrid, (1ª ed., en neerlandés, 1985; la trad. castellana es de la versión inglesa de 1990).

Pirson, J., 1898, Le style des inscriptions latines de la Gaule, Lovaina.

Pirson, J., 1901, La langue des inscriptions latines de la Gaule, Bruselas.

Pottier, B., 1974 = 1977, Lingüistica general. Teoría y descripción, Madrid.

Poukens, J.B., 1912, Syntaxe des inscriptions latines d'Afrique, Lovaina.

Reisig, Ch.K., 1888, Vorlesungen ueber latenische Sprachwissenschaft mit den Annerkungen von Fr. Haase (III: Lat. Syntax, neu bearbaitet von J.H. Schmalz und G. Landgraf), Berlín.

Richardson, L.J.D., 1936, «The dative of agent in Horace's Odes», $C R$ L, pp. 118-120.

Riemann, O., $1942^{7}$, Syntaxe latine d'après les principes de la grammaire historique, París.

Riesco Chueca, P., 1995, Pasionario hispánico (Introducción, Edición crítica y Traducción), Sevilla.

Rivero García, L., 1998, «Revisión de estudios sobre el orden de palabras en latín», Tempus XVIII, pp. 34-68.

Roby, H.J., 1871-1874, Grammar of the Latin Language from Plautus to Suetonius (I-II), Londres.

Rodrigues Aristar, A., 1996, «The relationship between Dative and Locative: Kurylowicz's Argument from a Typological Perspective», International Journal for Historical Linguistics XIII, pp. 207-224.

Rosén, H.B., 1992, «"Having” in Petronius», Pegasus devocatus. Studia in honorem H.C. Schnurr (Supplementa Humanistica Lovensia VII), pp. 101-117.

Rubio, L. (1989³), Introducción a la sintaxis structural del latín, Barcelona.

Rumpel Th. (1845), Casuslehre in besonderer Beziehung auf die griechische Sprache, Halle.

Sánchez Salor, E., 1994, «Los casos en las pasivas panis datur filio / filius docetur doctrinam a matre», Anuari de Filología XVII, pp. 107-114.

Schäfler, J., 1884, Die sogennanten syntaktischen Graecismen bei den augusteischen Dichtern (Münchener Diss.), Progr. Amberg.

Scherer, A., 1975, Handbuch der lateinischen Syntax, Heidelberg. 
Schlossarek, M., 1913, Sprachwissennchaftliche-vergleichende Kasusbetractung im Lateinischen und Griechischen, Breslau.

Schrijnen, J. - Mohrmann, Ch., 1936-1937, Studien zur Syntax der Briefe des hl. Cyprian (I-II), Nimega.

Sedlak, Ph.A.S., 1975, «Direct/Indirect Object Word Order», Working Papers in Language Universals XVIII, pp. 164-177.

Seelisch, Ricardus, 1872, De casuum obliquorum Valerium Maximum usu Liviani et Tacitei dicendi generis ratione habita, Münster, Diss.

Semple, L.B., 1895, «The dative in general», The Princeton College Bulletin 7, 36-41 (Abstract de una Tesis Doctoral presentada en 1895).

Serbat, G., 1981 = 1988), Casos y funciones. Estudio de las principales doctrinas casuales, de la Edad Media a nuestros días, Madrid.

Serbat, G., 1982, «Le système casuel est-il systématique?», REL LIX, pp. 298-317.

Serbat, G., 1983, «Le verbe sum. Syntaxe et sématique», VL XC, pp. 8-12.

Serbat, G., $1989^{\text {b }}$, «Le syncrétisme des cas: quelques réflexions», en G. Calboli (ed.), Subordination and other topics in Latin. Proceed. of the $3^{\text {rd }}$ Colloquium on Latin Lingusitics, Amsterdam, pp. 273-286.

Serbat, G., $1996^{\text {a }}$, «L'emploi des cas en latin», en Grammaire Fondamentale du Latin (VI/1-2), Lovaina

Sirbu-Dumitrescu, D., 1990, «Notas sobre el dativo posesivo en español y construcciones equivalentes en rumano», Letras de Deusto XLVI, pp. 133-149.

Skok, P., 1934, «Zum Balkanlatein (IV)», Zeitschrift für Romanische Philologie LIV, pp. 175-215, 424499.

Stolz, Fr.-Schmalz, J.H., 1910 4), Lateinische Grammatik (II/1,2), Múnich.

Svennung, J., 1922, Orosiana, Diss. Uppsala.

Teetz, F., 1885, De verborum compositorum apud Horatium structura, Diss. Halle.

Tesnière, L. (1959), Éléments de syntaxe structurale, París.

Théoret, M., 1982, Les discours de Cicerón. La concurrence du tour casuel et du tour prépositionnel, Montréal.

ThLL -Thesaurus Linguae Latinae (desde 1900), Leipzig.

Torrego, $M^{\text {a }}$.E., 1989, «Caracterización funcional de los sintagmas preposicionales en latín: pro + Abl., contra, adversus, in + Ac.», en Actas del VII CEEC, Madrid, pp. 609-616.

Touratier, Ch., 1969, reseña de R.T. Lakoff. Abstract Syntax and Latin Complementation, (1968), REL XLVII, pp. 106-121.

Touratier, Ch.,1978, «Quelques principes pour l'étude des cas (avec application à l'ablatif latin)», Langages L (Linguistique et latin), pp. 98-116.

Tovar, A., 1946, Gramática histórica latina, Madrid.

Tuggy, D., 1996-1998, «Dative-like construction in Orizaba Nahuatl», en W.van Langendock-W. van Belle (eds.), The dative (I-II), Amsterdam, t. I, pp. 407-452.

Velázquez Soriano, I. (1989), Las pizarras visigódas: Edición crítica y estudio, Murcia.

Veyrenc, J., 1975, «Fonction datif et factitif», en Mélanges linguistiques offerts à Émile Benveniste, Paris, pp. 519-526.

Villa, J. de la (1989), «Caractérisation fonctionelle du datif grec», Glotta LXVII, pp. 20-40.

Villar, F., 1981, Dativo y locativo en el singular de la flexión nominal indoeuropea, Salamanca.

Wölfflin, E., 1889, «Der Ablativus comparationis», ALL VI , pp. 447-467.

Woodcock, E.C., 1959, A new Latin Syntax, Londres.

Wüllner, F., 1827, Die Bedeutung der sprachlichen Kasus und Modi, Münster.

Wundt, W., $1912^{3}$, Völkerpsychologie (I-II), Leipzig [1ª ed. 1900; $2^{\text {a }}$ ed. 1904]. 